\title{
Packages for Terahertz Electronics
}

\section{This paper provides an overview of recent progress in interconnections and packaging technologies for the practical use of terahertz electronic devices and integrated circuits.}

By Ho-Jin Song

ABSTRACT | In the last couple of decades, solid-state device technologies, particularly electronic semiconductor devices, have been greatly advanced and investigated for possible adoption in various terahertz ( $\mathrm{THz}$ ) applications, such as imaging, security, and wireless communications. In tandem with these investigations, researchers have been exploring ways to package those $\mathrm{THz}$ electronic devices and integrated circuits for practical use. Packages are fundamentally expected to provide a physical housing for devices and integrated circuits (ICS) and reliable signal interconnections from the inside to the outside or vice versa. However, as frequency increases, we face several challenges associated with signal loss, dimensions, and fabrication. This paper provides a broad overview of recent progress in interconnections and packaging technologies dealing with these issues for $\mathrm{THz}$ electronics. In particular, emerging concepts based on commercial ceramic technologies, micromachining, and 3-D printing technologies for compact and lightweight packaging in practical applications are highlighted, along with metallic split blocks with rectangular waveguides, which are still considered the most valid and reliable approach.

KEYWORDS I LTCC; metallic split-block waveguide; quasi-optical THz packages; silicon micromachining; terahertz packages; $\mathrm{THz}$ electronics; 3-D printing

\section{INTRODUCTION}

For the last 100 years or more, there has been continual interest in the terahertz $(\mathrm{THz})$ regime [1], commonly referred as the frequency range of $0.1 \sim 10 \mathrm{THz}$. However, the spectral region located between microwaves and lightwaves in the electromagnetic spectrum is still being referred to as the forbidden region. Initially, the $\mathrm{THz}$ wave band was investigated as a part of the heat energy [2], and thus the lack of reliable sources and

Manuscript received August 5, 2016; accepted November 6, 2016. Date of publication January 16, 2017; date of current version May 18, 2017.

The author was with NTT Device Technology Laboratories, Kanagawa 243-0198, Japan. He is now with the Department of Electrical Engineering, Pohang University of Science and Technology (POSTECH), Gyeongbuk 37673, South Korea (e-mail: hojin_song@postech.ac.kr). detectors [3]-[7] was the most serious technical barrier. The Golay cell [8], backward-wave oscillators [9], n-InSb electron bolometer [10], Ge bolometer [11], and pyroelectric detectors [12] invented between the 1940s and the 1970s allowed infrared spectroscopy systems to reach the THz region. Meanwhile, there had been various early trials for novel $\mathrm{THz}$ applications other than spectroscopy [13]. And, at the end of the 1980s, the time domain spectroscopy (TDS) system was first demonstrated [14], [15]. THz generation and detection technologies with photoconductive antennas driven by a femtosecond pulsed lasers [16], [17] offered more reliable measurement over larger bandwidths and triggered further in-depth investigations on the THzwave applications. With these new technologies, more stable experiments for spectroscopic analysis of biotissues [18], [19], pharmaceutical materials [20]-[22], concealed objects [23], and toxic gases at remote sites [24] have been conducted. Consequently, $\mathrm{THz}$ waves are attracting more attention from various scientific and industrial fields, including materials, biomedical, nondestructive testing, industrial quality control, security, and so on. Meanwhile, the performance of semiconductor electron devices, typically transistors [25]-[28] and diodes [29]-[31], has been consistently improved, particularly in operating frequency or switching speed. The cutoff frequencies of state-of-the-art compound semiconductor transistors on InP or GaAs substrates have already exceeded $1 \mathrm{THz}$ [32], [33]. Utilizing such devices, several functional circuits and components, including amplifiers [34]-[37], oscillators [38]-[40], modulators/demodulators [41]-[43], and phase locked loops [44], [45], have been reported for $\mathrm{THz}$ applications. It is expected that, by deploying approaches similar to those used for ordinary RF and microwave electric appliances and equipment based on electric circuits and components, THz electronics will enable us to implement those applications more feasibly and practically [46]-[49].

As described above, $\mathrm{THz}$ generation and detection have been the most essential challenges for a long time. Plenty of research has been conducted and has finally resulted in quite competitive performance in the signal-to-noise ratio. 


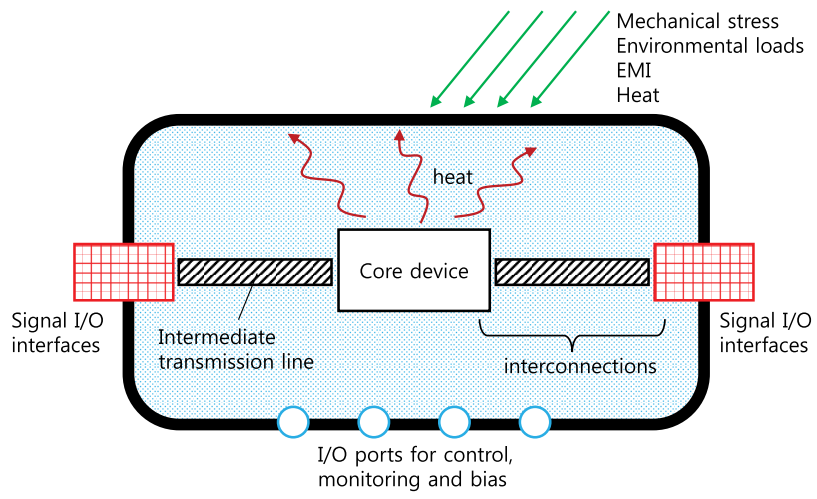

Fig. 1. Conceptual diagram of relationship between packaging and core device.

Accordingly, interest in the practical use of THz waves has been steadily growing in various fields and other technical issues are starting to attract more attention. One of those issues is how to package $\mathrm{THz}$ devices for practical applications.

Fig. 1 illustrates the relationship between packaging and the core devices. In general, packaging provides physical support, housing, and protection from mechanical stress, environmental loads, and electromagnetic interference and helps the core devices work under a thermally stable condition [50], [51]. In addition, appropriate input and output (I/O) interfaces for signal inputs/outputs, control, monitoring, and bias are formed on packages and interconnected with the core devices so that they can appropriately interact with external circuits, components, and systems. For ordinary integrated circuits (ICs) operating at microwave frequencies or lower, various types of plastic molding packages with metal beam leads or balls for I/O pins are being commonly employed [52]. Core devices are mounted in the package frame with conductive epoxy, and signal pads on the devices are wire-bonded to internal metal leads or pins. And, finally, the entire assembly is encapsulated with a mold compound. However, as frequency increases into the $\mathrm{THz}$ region, we are not able to employ the techniques as we did at low frequencies because of several challenges associated with signal loss, dimensions, and fabrication. The inductance of bonding wire, typically $1 \mathrm{nH} / \mathrm{mm}$ [53], is not ignorable even at millimeter-wave frequencies. In order to minimize the associated inductance and the reflection at $\mathrm{THz}$ frequencies, the wire length should be kept as short as possible. Sometimes, the required wire length should be shorter than the fabrication tolerance. The signal interface for low reflection I/Os is also an issue. It is hard to imagine using the reflow soldering technique at $\mathrm{THz}$ frequencies: The pads and beam leads required for the soldering process are too large; therefore, excitation of multimodes, radiation, and reflection would inevitably arise. For test and measurement instruments and equipment, waveguide (WG) structures such as coaxial connectors are commonly used. However, though coaxial structures can avoid dispersion problems over broad bandwidth because they provide the TEM mode as a fundamental mode [54], the connector dimensions will be impractically small for $\mathrm{THz}$ signals. For instance, in order to deliver $300-\mathrm{GHz}$ signal in a coaxial waveguide structure, the diameters of the inner conductor and outer dielectric should be smaller than approximately 0.2 and 0.46 mm, respectively (assuming 50- $\Omega$ characteristic impedance and air dielectric). With such a tiny inner conductor, it would be hard to maintain the durable and reliable interfaces required for practical applications [55].

Recently, THz packaging technologies have been investigated in attempts to deal with signal loss, dimension, and fabrication issues for $\mathrm{THz}$ electronics. In this review, recent progress in interconnections and packaging technologies will mainly be overviewed, particularly in the frequency range of $0.1 \sim 3 \mathrm{THz}$, where state-of-the-art electronic devices can operate. Emerging concepts based on commercial ceramic technologies, micromachining, and 3-D printing technologies for compact and lightweight packaging in practical applications are highlighted, along with metallic split blocks with rectangular WGs, which are still considered the most valid and reliable approach. First, in Section II, the limitations of traditional techniques at $\mathrm{THz}$ frequencies are overviewed in terms of materials, interconnections, and signal interfaces. Several examples of the traditional techniques for $\mathrm{THz}$ bands and emerging technologies with new materials or design approaches are reviewed in Sections III and IV, respectively. Section V discusses the potential of quasi-optic packaging techniques for $\mathrm{THz}$ applications, followed by the conclusion of the paper in Section VI.

\section{TRADITIONAL TECHNIQUES}

In general, technical issues related to the packaging can be divided into three topics: materials, circuit interconnections, and signal I/O interfaces. In this section, they will be briefly overviewed and discussed for $\mathrm{THz}$ applications

\section{A. Materials}

The package body, including signal pins, covers, and frames, is composed of various materials, such as metals, ceramics, plastics, and some composite ones. Core devices in the package are surrounded by some of these materials and signals from or to the devices pass through them. In general, the electrical, thermal, and physical properties of packaging materials mainly determine the corresponding performance of the packages. Therefore, accurate material parameters must be available for designing a desired package. Narrowing the topic to $\mathrm{THz}$ packages here, it is obvious that accurate characterization of potential materials, particularly for electrical properties, such as dielectric constants and loss tangents at those high frequencies, should be carried out. Since the 1960s, there have been a lot of reports for various dielectrics at up to $2 \mathrm{THz}$ or more. In [56], many of the original Fourier transform infrared measurements conducted at down to $20-30 \mathrm{GHz}$ are listed. In this paper, some of the recent results, in particular for materials likely to be utilized in THz packages, are summarized in Table 1 at 0.5 and $1 \mathrm{THz}$ [15], [57]-[68] for direct comparison. Overall, for the summarized materials, strong absorption at specific 
Table 1 Summary of Dielectric Constant and Tangent Loss for Various Materials at 0.5 and $1 \mathrm{THz}$ Reported in Literatures. (Note: Some of the Data Are From Graphs in the Literature)

\begin{tabular}{|c|c|c|c|c|c|c|}
\hline \multirow[b]{2}{*}{ material } & \multicolumn{2}{|c|}{$0.5 \mathrm{THz}$} & \multicolumn{2}{|c|}{$1 \mathrm{THz}$} & \multirow[b]{2}{*}{ ref } & \multirow[b]{2}{*}{ note } \\
\hline & $\varepsilon_{\mathrm{r}}$ & $\tan \delta$ & $\varepsilon_{\mathrm{r}}$ & $\tan \delta$ & & \\
\hline \multirow{3}{*}{ InP } & & & 12.33 & 0.009 & [65], Hejase 2011 & \\
\hline & & & 12.39 & 0.006 & [66], Dorney2001 & \\
\hline & 12.7 & 0.009 & & & own data & \\
\hline GaAs & 12.9 & 0.024 & 12.91 & 0.013 & $\begin{array}{l}\text { [15], Grischkowsky } 19 \\
90\end{array}$ & \\
\hline \multirow{2}{*}{ Si (doped) } & 11.85 & 0.025 & 11.85 & 0.01 & [65], Hejase 2011 & $\begin{array}{c}\text { doped wafer (concentration: unclea } \\
\text { r) }\end{array}$ \\
\hline & 9.91 & 0.001 & 9.91 & 0.001 & $\begin{array}{c}\text { [15], Grischkowsky } 19 \\
90\end{array}$ & high resistivity (>10Kohm $\mathrm{CM}$ ) \\
\hline \multirow{2}{*}{ Sapphire (A-plane) } & 9.41 & 0.01 & 9.43 & 0.031 & $\begin{array}{c}15], \text { Grischkowsky } \\
1990 \\
\end{array}$ & C-axis $\perp$ pol \\
\hline & 11.61 & 0.008 & 11.66 & 0.032 & $\begin{array}{l}\text { [15], Grischkowsky } \\
1990\end{array}$ & C-axis // pol \\
\hline \multirow[t]{2}{*}{$\mathrm{Al} 2 \mathrm{O3}$} & & & 9.3 & 0.003 & [65], Hejase 2011 & \\
\hline & & & 9.28 & 0.004 & [60], Bolivar2003 & \\
\hline LTCC \#1 (5.53@) & 5.43 & 0.053 & & & own data & $0.1 \mathrm{~mm} 10$ layers \\
\hline LTCC \#2 (7.1) & 6.71 & 0.072 & & & own data & $0.1 \mathrm{~mm} 10$ layers \\
\hline \multirow{4}{*}{ Quartz } & & & 3.84 & 0.004 & [65], Hejase 2011 & \\
\hline & & & 3.84 & 0.0037 & {$[67]$, naftaly 2007} & \\
\hline & 4.44 & 0.002 & 4.45 & 0.005 & $\begin{array}{c}{[15], \text { Grischkowsky } 19} \\
90\end{array}$ & A-plane, $\mathrm{C}$-axis $\perp$ pol \\
\hline & 4.64 & 0.004 & 4.64 & 0.003 & $\begin{array}{c}\text { [15], Grischkowsky } 19 \\
90\end{array}$ & A-plane, C-axis // pol \\
\hline \multirow[t]{2}{*}{ Pyrex Glass } & & & $4.48 @ 0.8 \mathrm{THz}$ & $\underline{0.052 @ 0.8 T \mathrm{TH}}$ & [65], Hejase 2011 & \\
\hline & & & 4.45 & 0.05 & [67], naftaly 2007 & \\
\hline $\mathrm{RO} 010$ & 12.5 & 0.025 & 14 & $>0.15$ & {$[65]$, Hejase 2011} & graph read \\
\hline $\mathrm{RO} 0006$ & 8 & 0.015 & 9 & $>0.15$ & [65], Hejase 2011 & graph read \\
\hline $\mathrm{RO} 003$ & 3.2 & 0.01 & 3.2 & 0.02 & {$[65]$, Hejase 2011} & graph read \\
\hline \multirow{2}{*}{ polytetrafluoroethylene (PTFE) } & & & 2.06 & 0.0004 & {$[65]$, Hejase 2011} & \\
\hline & & & 2.08 & 0.008 & [62], Jin2006 & \\
\hline liquid crystal polymer (LCP) & 3.5 & 0.02 & 3.51 & 0.05 & [65], Hejase 2011 & graph read \\
\hline polyimide (dry) & & & 3.27 & 0.021 & [65], Hejase 2011 & \\
\hline \multirow{3}{*}{ polyimide (air) } & & & 3.37 & 0.037 & {$[65]$, Hejase 2011} & \\
\hline & 3.28 & 0.098 & 3.24 & 0.11 & [62], Jin2006 & graph read \\
\hline & 3.42 & 0.001 & & & & \\
\hline \multirow[t]{2}{*}{ Polycarbonate $(\mathrm{PC})$} & & & 2.61 & 0.027 & [65], Hejase 2011 & \\
\hline & & & 2.67 & 0.028 & {$[67]$, naftaly 2007} & \\
\hline \multirow[t]{2}{*}{ Zeonor } & & & 2.35 & 0.001 & [65], Hejase 2011 & \\
\hline & & & 2.28 & 0.001 & [68], Podzorov2008 & \\
\hline \multirow{3}{*}{$\begin{array}{l}\text { high-density polyethylene } \\
\text { (HDPE) }\end{array}$} & & & 2.36 & 0.002 & [65], Hejase 2011 & \\
\hline & & & 2.37 & 0.002 & [67], naftaly 2007 & \\
\hline & 2.36 & 0.013 & 2.35 & 0.009 & [62] Jin2007 & \\
\hline \multirow{2}{*}{ PET } & & & 2.98 & 0.031 & [65], Hejase 2011 & \\
\hline & 2.95 & 0.054 & 2.93 & 0.063 & {$[62], \operatorname{Jin} 2006$} & \\
\hline $\begin{array}{c}\text { benzocyclobutene } \\
(B C B)\end{array}$ & & & $2.41-2.53$ & $0.0042-0.039$ & [63], Perret2008 & membrine structure \\
\hline $\begin{array}{l}\text { photopolymer resin } \\
\text { (acrylic-based) }\end{array}$ & & & $2.89-2.56$ & 0.06 & [64] Younus2009 & 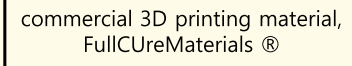 \\
\hline
\end{tabular}

frequencies has rarely been observed, and loss tangents gradually increase with respect to frequency. In addition, there is no significant deviation between measurements reported by multiple groups. Though it would be hard to generalize with the limited data, the parameters listed in Table 1 should give readers a good initial idea about how these dielectrics could be used in THz packages.

In fact, the question of what kind of packages should be made with what materials for $\mathrm{THz}$ applications is another substantial problem, which should be discussed together with the new fabrication technologies and design principles. A couple of examples of this issue will be presented later.

\section{B. Circuit Interconnections}

In many packaging technologies, bonding wires are being commonly used to interconnect a core IC or device to another one or to an additional substrate. As operating frequency increases, the associated inductances of the wires cause significant reflection, which degrades the performance of the packaged devices. The inductances strongly depend on the geometry of the wires, such as their diameter, loop height, and length [53], [69], [70]. Therefore, fine and repeatable bonding techniques are essential. Simple circuit models for the wires enable us to compensate for the parasitics with an extra circuit or 


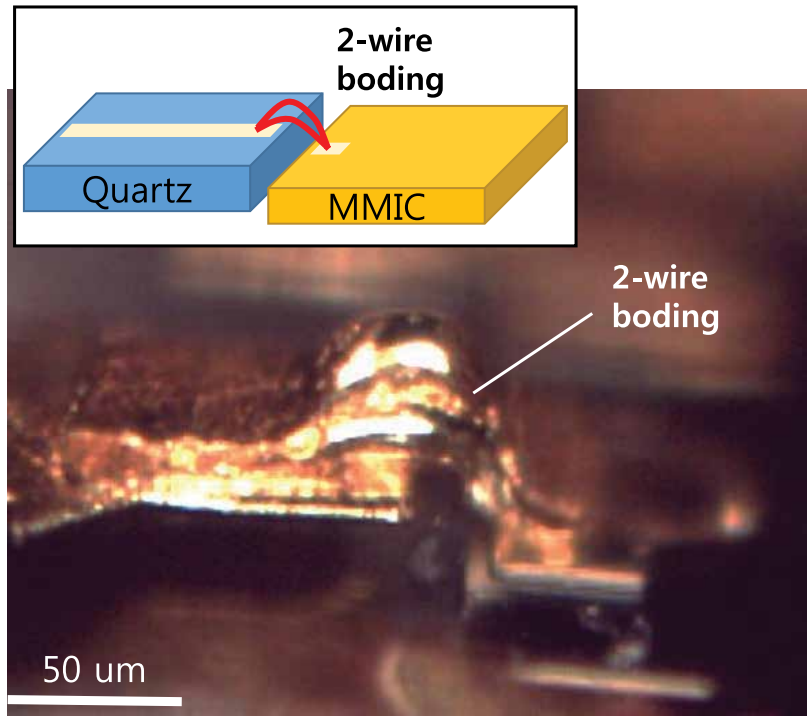

Fig. 2. Sideview of two-wire bonding for signaling at up to $350 \mathrm{GHz}$ between InPMMIC and quartz substrate (inset: schematic view).

structure in ICs and substrates, sometimes with multiple wires. However, as the frequency increases further above $100 \mathrm{GHz}$, the wires start to behave as a distributed component like transmission lines. Simply shortening them can effectively reduce wire inductances even for up to $300 \mathrm{GHz}$ [71]-[73]. With in-house fabrication, multiple wires can be bonded at the given pads (see Fig. 2) to minimize the effect of the wires. However, this is not a proper solution for practical applications when one considers the need for thermal durability and performance uniformity between modules. In [74], bonding wires were treated as a high-impedance transmission line with approximately $100-\Omega$ characteristic impedance and used as an imped-

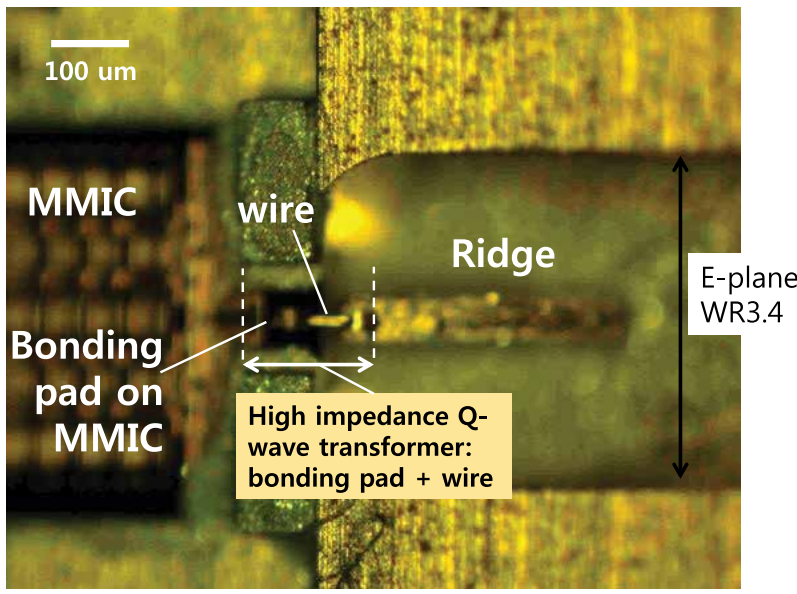

Fig. 3. Photo of CPW-to-rectangular waveguide transition with high impedance quarter wavelength transformer consisting of bonding pad and wire, and ridged waveguide. Figure from [74]. (a)
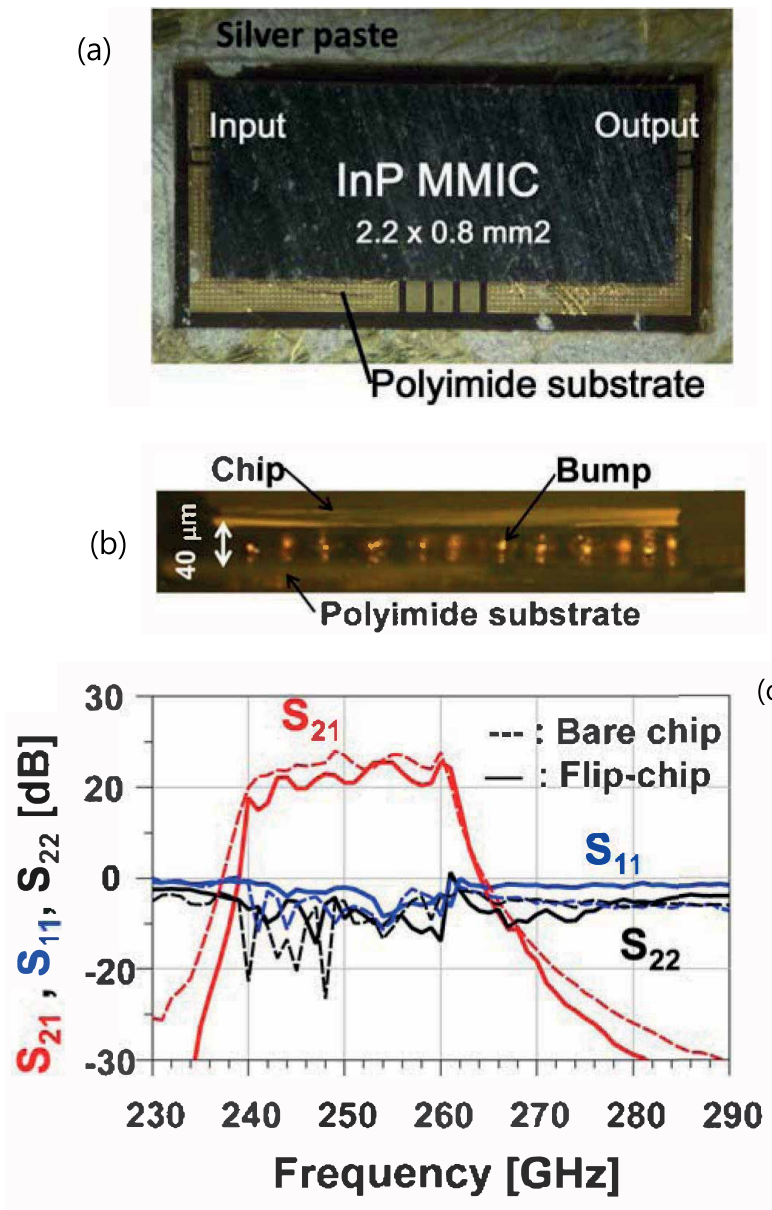

Fig. 4. (a) Top view and (b) side view photographs of flip-chip mounted MMICs and (c) measured S-parameters before and after flip-chip bonding. Figure from [77].

ance transformer between the $50-\Omega$ coplanar waveguide (CPW) to a ridge WG.

Flip-chip bonding is also an attractive technique for interconnecting millimeter and $\mathrm{THz}$ signals, owing to the small intrinsic parasitics associated with bump transitions [75]. There have been just a couple of demonstrations of the flipchip bonding technique at 250 and $300 \mathrm{GHz}$. In [76], a 10- $\mu \mathrm{m}$ AuSn bump formed by a direct evaporation and lift-off process exhibited insertion loss of less than $1 \mathrm{~dB}$ per transition and return loss larger than $10 \mathrm{~dB}$ at up to $250 \mathrm{GHz}$. Kawano et al. reported a flip-chip-mounted InP high electron mobility transistor (HEMT) amplifier monolithic microwave integrate circuit (MMIC) on a polyimide motherboard [77]. Suppressing the substrate mode in the motherboard and the resonance of current flowing in ground paths was noted as the most critical point for successful results. Though the bump height of around $40 \mu \mathrm{m}$ was quite large, no serious degradations of return loss and gain of the MMIC were observed. In spite of these successful demonstrations, a few issues should be considered for $\mathrm{THz}$ devices. Chip detuning, dielectric loading at transitions, the influence of underfill materials, and substrate 


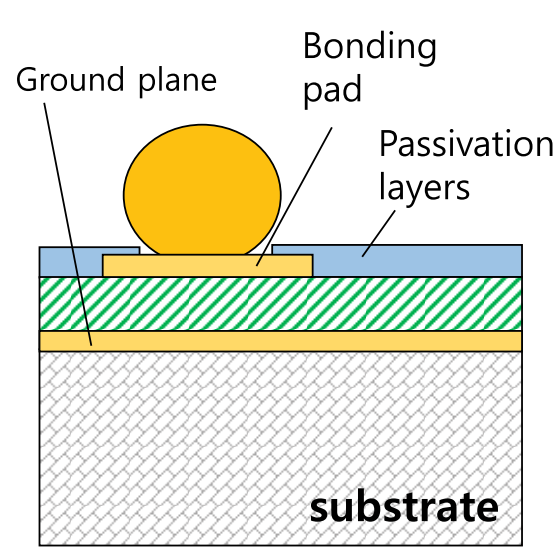

(a)

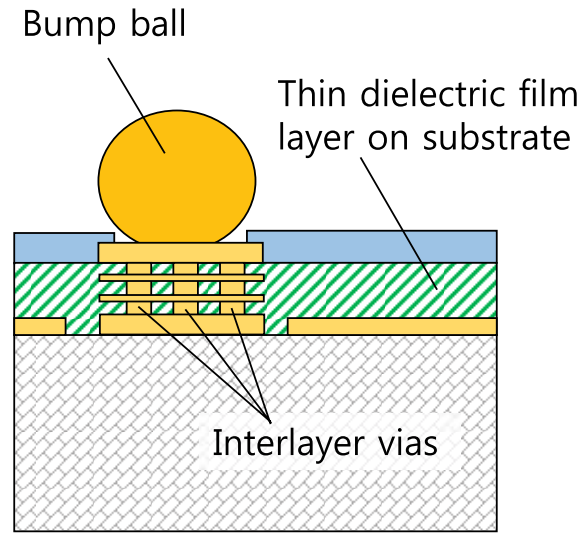

(b)

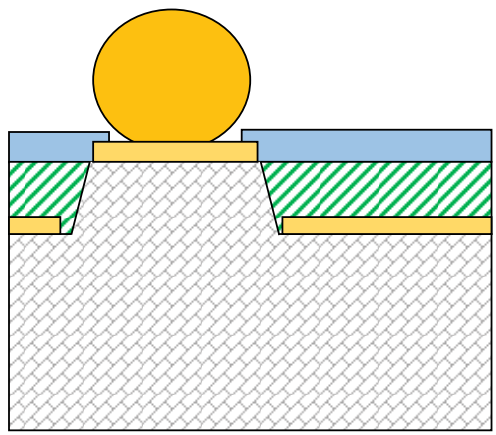

(c)

Fig. 5. Three typical bonding pads in MMICs: (a) bond over active structure; (b) bond pad consisting of multimetal layers connected with interlayer vias; and (c) bond pad on substrate bump.

modes coupling at motherboards are common drawbacks of the flip-chip bonding technique [78], [79]. Among them, one dilemma we would face related to the bonding pad structure in MMICs and/or MMIC thickness at THz frequencies will be briefly addressed here. Fig. 5 shows some examples of bonding pad structures. The structures illustrated in Fig. 5(b) and (c) are commonly used in MMICs based on silicon metaloxidesemiconductor (MOS) technologies and compound semiconductors. However, in those structures, bonding pads are opened to the substrate and would therefore be a source of substrate mode excitation at $\mathrm{THz}$ frequencies. To avoid this, the wafers have been thinned down to $50 \mu \mathrm{m}$ for $300-\mathrm{GHz}$ amplifiers [43], $25 \mu \mathrm{m}$ for 650-GHz amplifiers [37], and $18 \mu \mathrm{m}$ for 1-THz amplifiers [28]. As can be easily expected, with the thinned chip, mechanical wafer breakage or cracks would easily occur during the flip-chip bonding process. If a multilayer metallization process is available, like complementary metaloxidesemiconductor (CMOS), a shield ground metal layer can be inserted under the bonding pads, as shown in Fig. 5(a), to suppress the substrate mode excitation even with no wafer thinning. However, in this case, the ground shield dramatically increases the capacitance of the bonding pad and thereby considerably degrades return loss performance at the transition.

\section{Signal Interfaces}

Packages should provide appropriate signal interfaces that can deliver signals from external circuits to internal MMICs and vice versa. To maintain the time-dependent amplitude of the signals, the simple metal wires used at low frequencies should be replaced with transmission line structures that have a given characteristic impedance and are nondispersive over the desired frequency band. It would be fantastic if we could deploy the solder balls or leads commonly incorporated with the reflow soldering process for low-frequency applications to $\mathrm{THz}$ packages. However, to the best of my knowledge, we have no technical clues about how this might be accomplished. On the other hand, assuming the solder balls or leads should configure some sort of WG structure for $\mathrm{THz}$ operation, one may have reasonable questions about the dimensions of the signal interface structures the thickness of motherboards, the thickness of solder metal, the minimum spacing between the balls or leads, and so on.

Incorporating RF connectors generally used for test instruments is an option. In particular, coaxial WGs are attractive due to their broadband operation bandwidth from direct current (dc) and nondispersive propagation characteristics in the band. However, as frequency increases, the $\mathrm{TE}_{11}$ mode starts to become excited and single-mode operation is no longer guaranteed. Fig. 6 shows the calculated

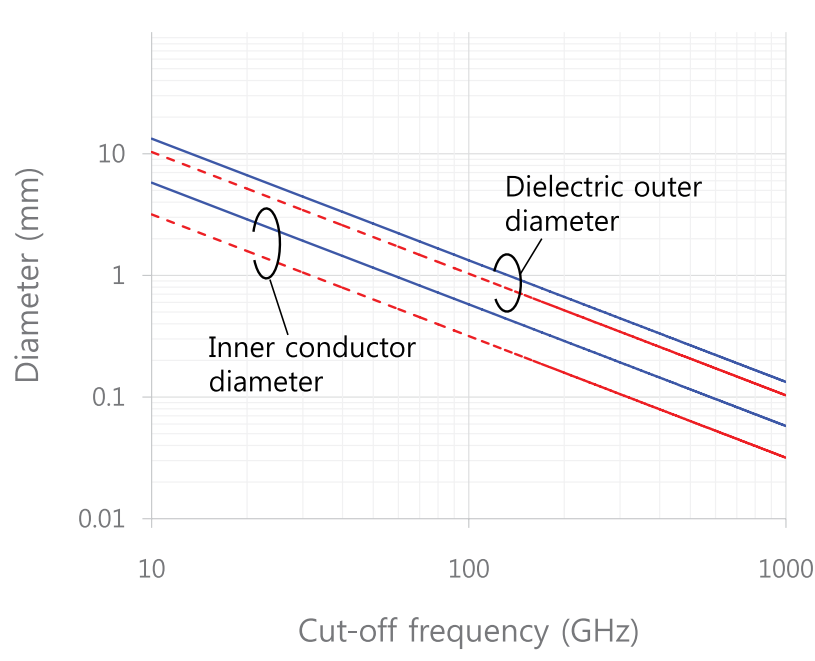

Fig. 6. Calculated dimensions of $50-\Omega$ coaxial waveguide with respect to cutoff frequency for TEM single mode operation. (Solid line: $\varepsilon_{r}=$ 1. Dashed line: $\varepsilon_{r}=$ 2.) 


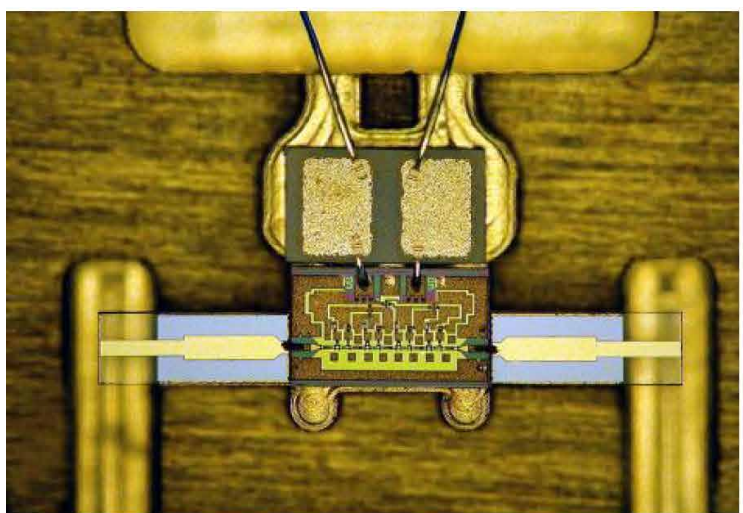

(a)

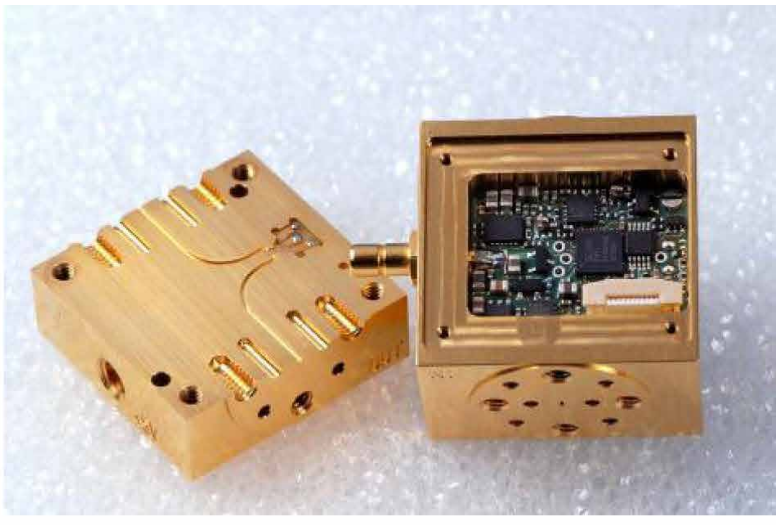

(b)

Fig. 7. (a) Closeup and (b) microview of 300-GHz mHEMT amplifier split-block module with E-plane probes on quartz substrate and wire bonds. Figure from [73].

dimensions of $50-\Omega$ coaxial connectors with respect to the cutoff frequency of the $\mathrm{TE}_{11}$ mode. Even with no dielectric between the inner and outer conductors, the diameter of the center pin should be as small as $0.2 \mathrm{~mm}$ for the 300$\mathrm{GHz}$ cutoff frequency. Considering a mechanical contact is required for coaxial connectors, such a tiny center pin would not be suitable for the durable and reliable interfaces required for practical applications.

Even with various drawbacks such as their bulky structure and limited operating bandwidth, rectangular WGs are still considered the most appropriate interfaces for $\mathrm{THz}$ packages because of their superior features of low loss, excellent durability, and a reliable and repeatable mating system. Large flange structures with alignment pins and screw taps for mating give us a bulky or mechanical impression. However, the dimensions of a rectangular WG itself are quite small at $\mathrm{THz}$ frequencies. Since WG interfaces are normally deployed in large-scale scientific facilities and military radar systems that require large power- and heat-handling capability [80] and superior electrical performance, WG flanges have so far been developed to

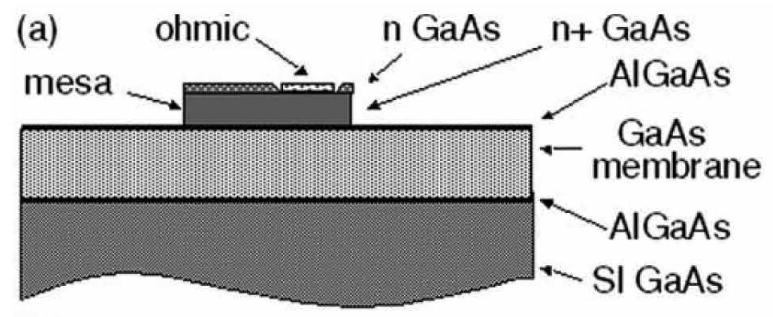

(b)
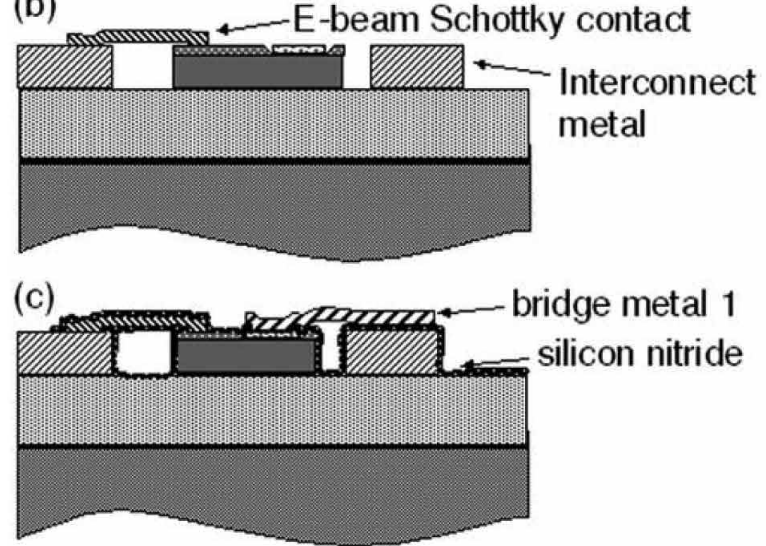

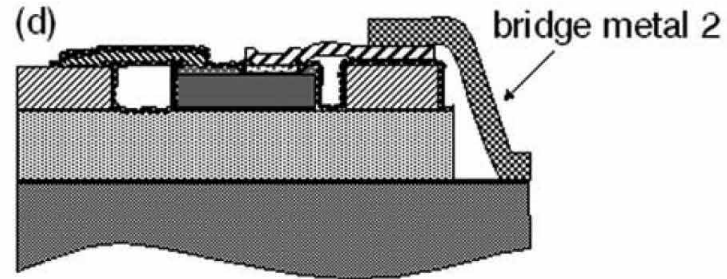

(e) - AlGaAs etch stop
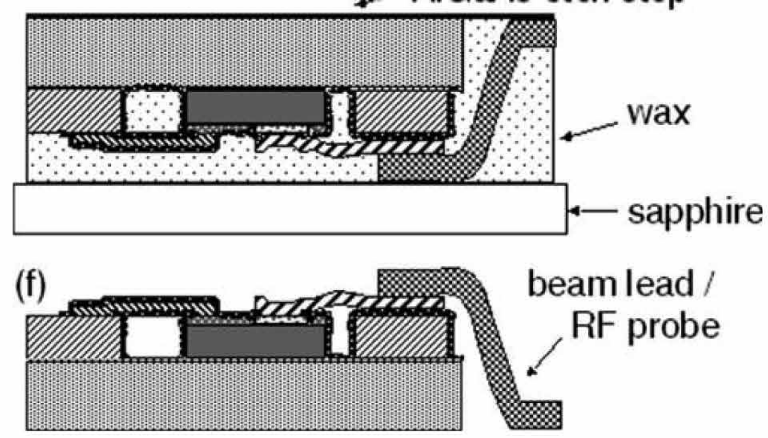

Fig. 8. Membrane device fabrication steps. (a) Ohmic and mesa definition. (b) Interconnect metal and E-beam defined Schottky deposition. (c) Passivation and bridge metal 1 definition. (d) Membrane layer etch and bridge metal 2 deposition. (e) Removal of substrate with selective etch. (f) Release of device from the carrier wafer. Figure from [86]. 
(b)

(a)

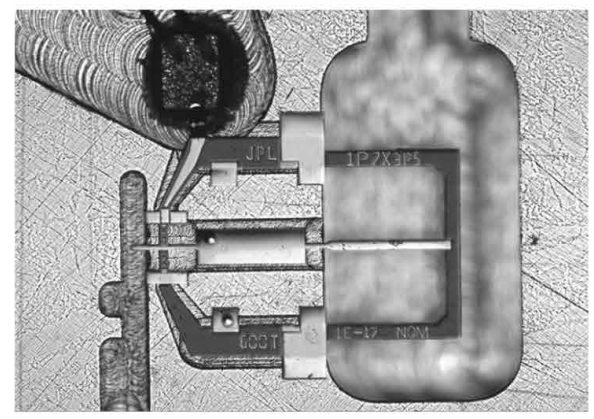

(c)

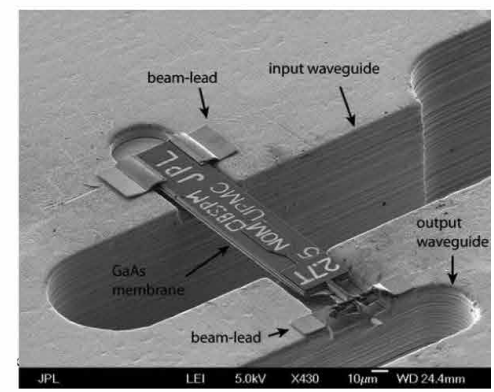

Fig. 9. Assembled diode-based frequency multipliers in split-WG blocks: (a) 600-GHz doubler; (b) 1.9-THz tripler; and (c) 2.7-THz tripler. Figures from [88], [87], and [92].

improve accuracy and repeatability [81], [82]. In other words, a new concept for a compact mating system for rectangular WGs would enable new sorts of packages at $\mathrm{THz}$ frequencies.

\section{METALLIC SPLIT-BLOCK WG THz PACKAGES}

Rectangular WG split blocks are commonly made one by one by using computer numerical control (CNC) milling processes. However, recent advanced milling machines provide quite fine manufacturing accuracy of around a few micrometers, which is acceptable for operations up to $3 \mathrm{THz}$. The waveguide modules should incorporate WG-to-microstrip line (MSL) or CPW transitions between core devices and rectangular WG ports. At millimeter-wave frequencies, transition circuits such as radial E-plane probes have been fabricated on a separate low-dielectric-constant substrate with a bonding wire in the RF path. Fig. 7 shows an internal view of a typical WG module [73]. As shown in the previous section, this approach would work fine up to around $300 \mathrm{GHz}$ [71]-[73], but, fundamentally, the associated inductance causes issues for bandwidth and module operation at frequencies beyond 200-300 GHz.

The popular approach to implementing a rectangular WG module at $\mathrm{THz}$ frequencies is to integrate the transition probes with the core devices or circuits. Particularly, there have been various demonstrations of diode-based frequency multiplier chains and mixers at up to approximately $3 \mathrm{THz}$ [83]-[93]. In those designs, the substrates of the MMICs have been thinned down to a few micrometers to reduce RF losses in the metal lines and to minimize dielectric loading of the WGs. The process steps for membrane-device fabrications are illustrated in Fig. 8. A part of the substrate under most of the transmission line or ground pad metals that form the beam leads should be completely removed. The beam leads provide ground and dc bias contact and help simplify assembly [83]-[86]. The beam leads lie directly on the block or bias chip capacitor, but no wire bonding, soldering, or epoxy attachment is needed. Heat generated by the active devices in the ICs can be effectively sunk via the large area metal beam leads to the metallic blocks [84]. Electrically, the beam leads can work as E-plane transition probes [83]-[86], [88]. Fig. 9 shows THz-frequency multipliers on GaAs membranes with metal leads for grounding and RF coupling.

Similar techniques have also been employed for active MMICs, such as amplifiers with radial probe or dipole electromagnetic transitions [35], [94]-[96]. The active MMICs should also be thinned down to achieve good coupling efficiency at the integrated transitions and suppress substrate modes by forming dense substrate vias. The substrate thickness and substrate modes are in a tradeoff relationship. Undesired substrate modes can be suppressed with the thinning process, but challenges will arise in fabrication and assembly. According to the literature, practical substrate thickness would be $50 \mu \mathrm{m}$ for the 300-GHz band[43], $25 \mu \mathrm{m}$ for the $650-\mathrm{GHz}$ band [37], and $18 \mu \mathrm{m}$ for the $1-\mathrm{THz}$ band [28]. The thinned MMICs are then mounted on a pedestal in one half of the split blocks so that the transitions can be aligned to the fields on the E-plane of the rectangular WG while they are suspended in the cavity (see Fig. 10). According to the literature, estimated coupling losses per transition are approximately $1 \mathrm{~dB}$ in the $340 \sim 380-\mathrm{GHz}$ band [97], $1.5 \mathrm{~dB}$ in the $460 \sim 500-\mathrm{GHz}$ band[35], and $1.52 \mathrm{~dB}$ in the $625 \sim 700-\mathrm{GHz}$ band [37].

Active MMICs require multiple dc pads, and sometimes a large number of transistors should be arrayed in parallel to drive large output powers [37], [96], which leads the larger chip widths. Dense substrate vias would prevent leakage propagation from the substrate around the transitions into 
(a)

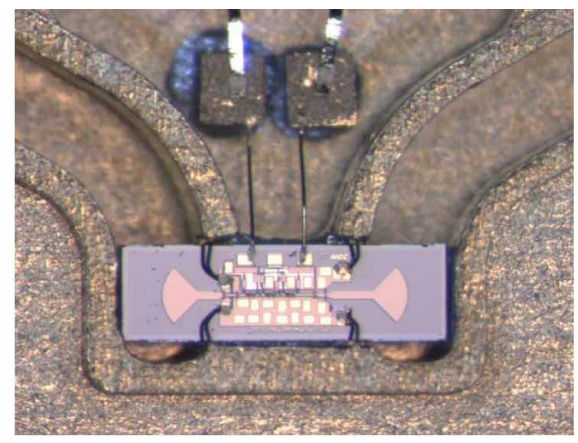

(b)

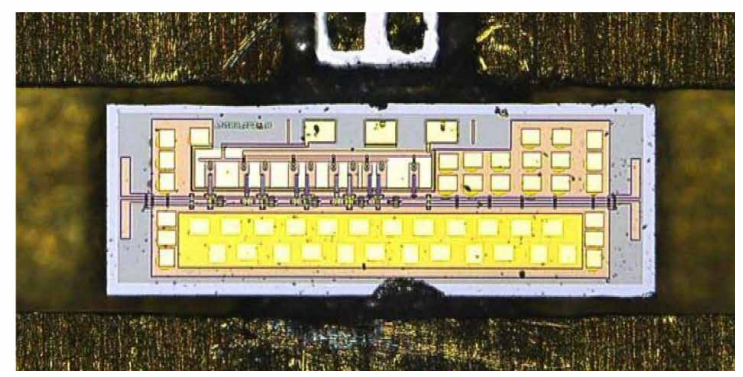

Fig. 10. (a) 300-GHz amplifiers with radial probe transitions and (b) 480-GHz low noise amplifier (LNA) with dipole probes in split-block package. Figures from [94] and [35].

the IC region. However, with large-chip-width MMICs, the E-plane probes could cause energy leakage from the WG into the chip channel that will finally be coupled to the opposite side WG port and undesired mode excitation in the packages, resulting in potential resonance or oscillation [97], [98]. A simple way to avoid the problem is to remove the corners of the MMICs beside the E-plane probe transitions so that the chip width becomes electrically narrow in the transition region. Such nonrectangular chip dies can be accomplished by chemical etching [37], [99] or a laser dicing singulation process [100]-[102]. Fig. 11 shows chip photographs of nonrectangular MMICs.

Obviously, the additional process for nonrectangular chips can be expensive and would cause a yield problem in fabrication, handling, or assembly steps. Recently, an integrated chip-to-WG transition for large-chip-width MMICs has been reported that provides a large degree of design-area freedom with no dedicated process [103]. In [103], the dipole probes are located on the corner of the test MMIC, whose width is approximately 2.5 times wider than the E-plane width of the rectangular WG. To accommodate such a large-chip-width MMIC, one cannot avoid forming a thin slit in the split block modules. In this structure, it was found that only a certain series of wave modes will be excited and confined in the air gap in the slit (see Fig. 12). Based on the understanding that the undesired modes stand above the MMIC perpendicularly and bypass it through the air gap, a piece of high-permittivity dielectric material such as a doped silicon was inserted into the chip channel to form a partially loaded space and accumulate the parasitic energy with a $\mathrm{Si}$ absorber. With this technique, 60- $\mathrm{dB}$ interport isolation was demonstrated with comparable insertion loss per transition probe in the 300 $\mathrm{GHz}$ band. Though the technique has not been proved with an active circuit yet, the work described in [103] suggests that similar in-depth analysis about the undesired modes would give us a chance to effectively suppress them even without expensive and dedicated fabrication processes.

\section{INEXPENSIVE WG PACKAGES}

Metallic WG packages have been used for the most successful millimeter- and THz-wave components, such as amplifiers, frequency multipliers, mixers, and detectors, owing to their superior performance in signal loss, compatibility with MMICs, and ease of design. However, in terms of cost and productivity, the fabrication process, as it is based on mechanical machining of every single piece, must be the dominant factor limiting the extension of $\mathrm{THz}$ technologies to large-scale applications in other than a couple of limited areas such as the military or science. There have been various and consistent efforts to maintain the advantages

(a)

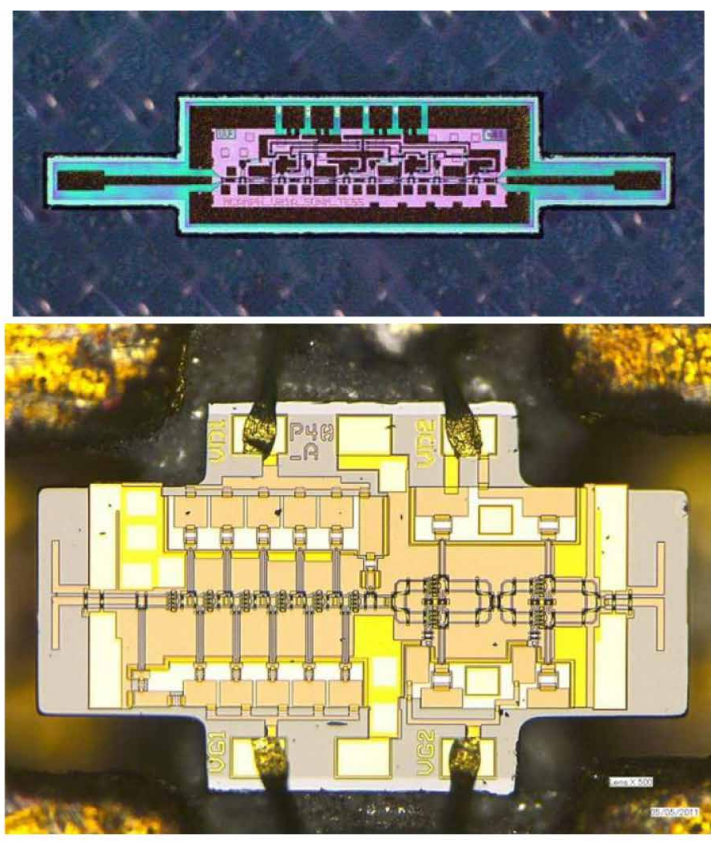

(c)

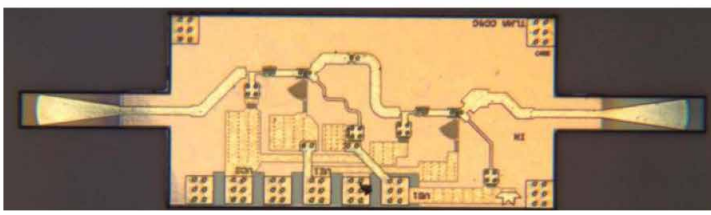

Fig. 11. Nonrectagular MMIC chip dies (a) H-band amplifier; (b) 650-GHz power amplifier; and (c) 300-GHz LNA. Figures from [100], [37], and [99]. 


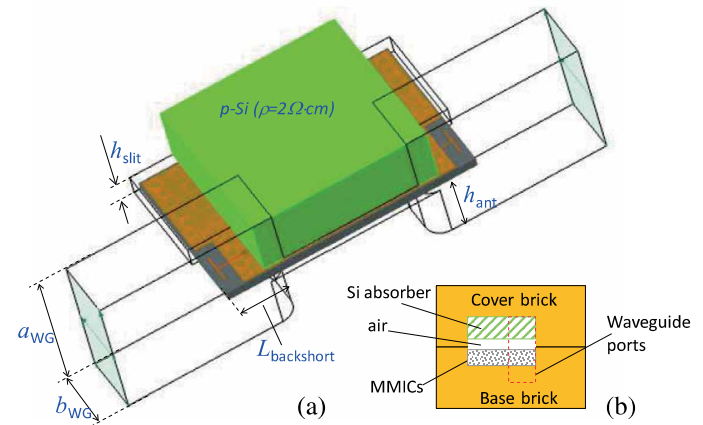

(a)

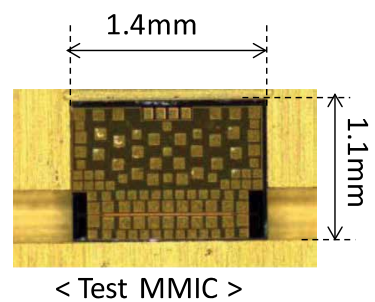

(c)

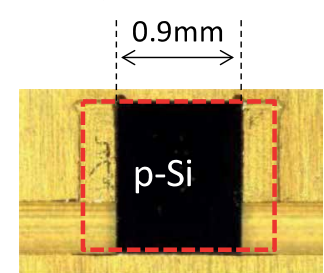

$<$ Absorber $>$
$<$ Test MMIC >
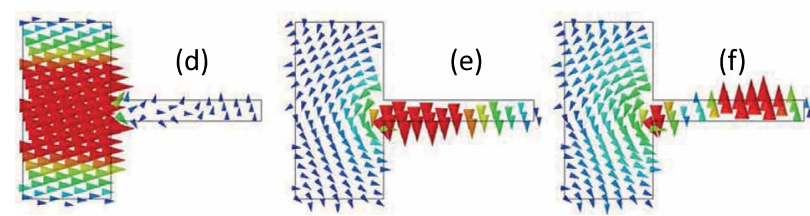

Fig. 12. (a) Schematic and (b) cross-sectional diagram of WR3.4 package with single slit and p-type si block as absorber; (c) photographs of mounted silicon absorber and test MMIC; and (d)(f) simulated E-field distribution of first three modes in slit WG. Figure from [103].

of using rectangular WGs for signaling and interfacing, but with novel fabrication technologies yielding better productivity at lower cost. In this section, several interesting approaches based on micromachining, a low-temperature co-fired ceramic (LTCC) technology, plastic modeling techniques, and 3-D printing technology will be overviewed.

\section{A. Silicon Micromachining}

As the operating frequency increases, the dimensions of devices and components, including antennas, transmission lines, and other related ones, shrink to a few tens of micrometers or even less. For such small structures, ordinary semiconductor fabrication processes, particularly etching and metallization, can be used with excellent tolerance and productivity. Surprisingly, a THz dielectric rod antenna fabricated by means of a micromachining process was already reported in the early 1980s [104].

WG components with silicon micromaching are also implemented in a split-block fashion using two pieces in the E-plane or the H-plane [105]. The fabrication steps are quite simple: 1) etch silicon wafers to form the partial or full depth of the WGs; 2) coat the surface with metals; 3) bond the two pieces to form the WG; and 4) coat the surface with metal again. There are three approaches for etchingwet, dry, and laser etching [106]-[109]. Wet etching has been successful at up to the WR-4 band (200-260 GHz). However, since wet chemical etchants come into contact with the whole surface, it is hard to obtain a shape with a high aspect ratio, a vertical profile at sidewalls, and sharp corners in the WGs. In contrast, deep reactive ion etching (DRIE) based on the Bosch process can yield sharper etching profiles than the wet process. With additional control on the DRIE process, such as the power ramp and cycle time for etching and passivation steps, arbitrary sidewall angles can be obtained as well [110]. Fig. 13 shows closeup scanning electron microscope (SEM) images of WGs fabricated with the dry process. The rough surface of the sidewalls and the imperfect corners of the WG would cause some discontinuity and additional losses. However, as can be seen in the brief summary from selected literature [105], [106], [109], [111] in Table 2, the insertion loss of the straight WGs looks good enough for many THz applications. With these micromachining processes, several WG passive components, such as antennas [107], [112]-[114], hybrid couplers [115], orthomode transducers [116], and frequency filters [117], [118], have been demonstrated.

Micromachined packages for $\mathrm{THz}$ MMICs can be implemented in similar fashion with metallic split blocks consisting of two pieces. In [119], a 585-GHz mixer based on a GaAs Schottky barrier diode on quartz substrate was packaged in silicon split blocks in which a horn antenna, quartz substrate channel, and alignment grooves were monolithically integrated. Metal shims were placed in the alignment groves to guide the two halves into place. The mixers exhibited performance as good as that of others packaged in the traditional way with a diagonal horn antenna.

By taking advantage of micromaching processes that yield high accuracy and repeatability in shape and dimensions, packages can be formed with multiple silicon pieces for more complex structures [89], [110], [112], [120], [121]. In general, metallic blocks are designed to make the RF signals flow in the plane on the split surface. However, the volume of the packages can be reduced a lot with a 3-D design of the signal path, and the 3-D structure can be implemented by slicing the dimensional structure vertically into multiple thin pieces. Fig. 14 illustrates a $600-\mathrm{GHz}$ receiver front-end

Table 2 Summary of Silicon Micromachined Waveguides

\begin{tabular}{|l|l|l|l|l|}
\hline Waveguide & $\begin{array}{l}\text { Frequency range } \\
(\mathrm{GHz})\end{array}$ & $\begin{array}{l}\text { Insertion loss } \\
(\mathrm{dB} / \mathrm{mm})\end{array}$ & process & reference \\
\hline WR-10 & $75 \sim 100$ & 0.015 & Wet & [107], Lubecke, 1998 \\
\hline WR-4 & $200 \sim 255$ & 0.31 & Wet & {$[$ [107], Lubecke, 1998 } \\
\hline WR-2.5 & $350 \sim 460$ & 0.086 & DRIE & {$[105]$, Kirby, 2006 } \\
\hline WR-1.5 & $500 \sim 750$ & 0.15 & DRIE & [109], Leong, 2012 \\
\hline WR-1.5 & $500 \sim 750$ & $0.08 \sim 0.1$ & DRIE & {$[111]$, Reck, 2014 } \\
\hline
\end{tabular}



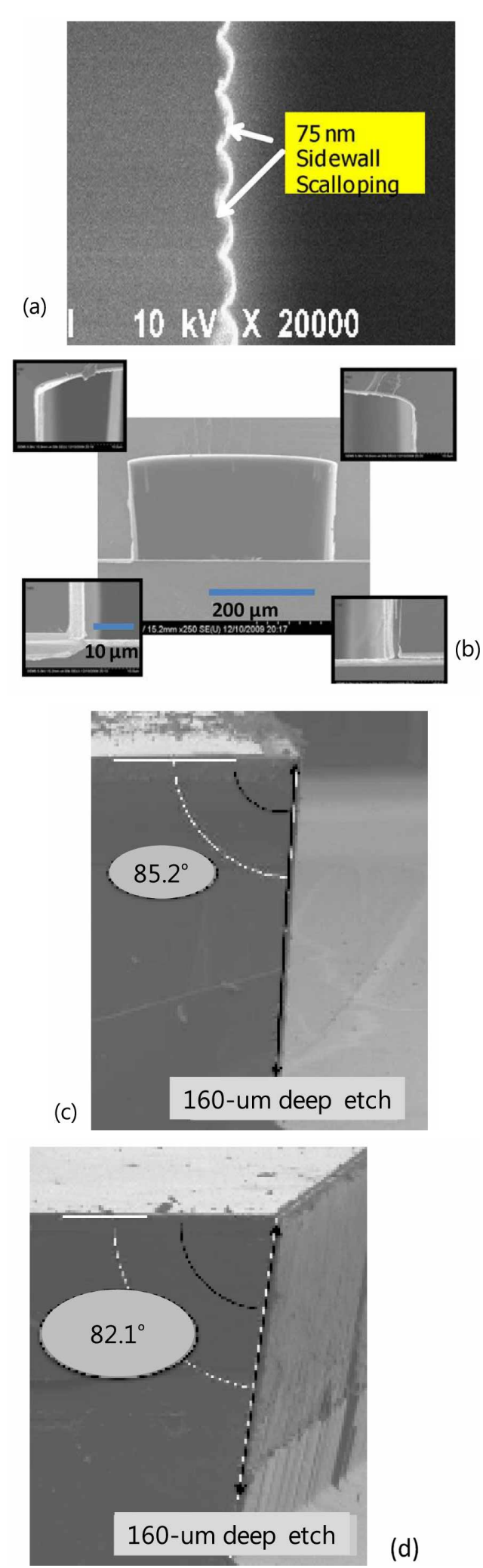

(d)

Fig. 13. SEM images of WGs fabricated with DRIE process. (a) Waveguide sidewall roughness; (b) WG face with closeup of corner junctions; WG sidewall with intentional angels of (c) 5 and (d) 8 , respectively. (a) and (b) are from [109], and (c) and (d) are from [110]. module packaged with four silicon micromachined pieces, which was reported in [112]. Though the micromachined module was assisted by a metallic horn antenna in that work, the horn antenna can be fabricated with the same process as well. Lee et al. reported a 20-dB corrugated horn antenna fabricated by stacking twenty-four $300-\mu \mathrm{m}$-thick silicon wafers in the 320-360-GHz band [114]. For higher frequency bands, a dielectric lens is an option requiring fewer stacked layers, with a final simple assembly as a result.

Another interesting approach for micromachined packages is based on the photolithography technique on silicon substrates. In [122], WG structures were formed by using metal electroplating over a photolithographically patterned thick photoresistor, SU-8. Thanks to the multiple photoresist layers for the mould, this technique enables us to implement a 3-D structure with the planar fabrication process at up to $1.3 \mathrm{THz}$.

\section{B. LTCC Packages}

Owing to its high integration capability and low cost for high volume production, LTCC technology has been widely studied for packaging millimeter-wave transceiver ICs, particularly 60-GHz radio front-ends [123], [124]. The stacking of multiple laminated substrates enables us to implement the substrate-in-waveguides (SIWs) [124]-[126] and antenna-in-a-package (AIP) [127]-[129] structures easily. LTCC technology can be deployed to manufacture a package structure similar to that shown in Fig. 14, which was implemented with multiple micromachined silicon wafers. One example of THz packages with LTCC technology is illustrated in Fig. 15. In this concept, a rectangular WG and microstripto-WG transition are monolithically integrated in the package body [130] and an MMIC is assumed to be mounted in the package with flip-chip bonding interconnections. As shown in the figure, the rectangular WG can be formed with multiple air-cavity layers and an array of vias along the edges of the air cavity. Since ordinary LTCC technology does not provide metal coating on the internal sidewalls of the air cavity, vias and metallization on every layer simulate the metallic wall inside the WG. Specifically speaking, it is a sort of corrugated WG with periodic dielectric loading. Therefore, the distance between the air-cavity edges and the interlayer vias, which would be equivalent to the corrugation depth in a corrugated WG, becomes a critical parameter determining the operation bandwidth of the WG [131]. Tajima et al. fabricated the straight WG section with a standard LTCC foundry process and experimentally demonstrated insertion loss of around $0.6 \mathrm{~dB} / \mathrm{mm}$ and return loss better than $15 \mathrm{~dB}$ in the 240-330-GHz band.

Instead of the WG in Fig. 15, a horn antenna can be used as an interface to the air. Based on the corrugated structure, a step-profiled pyramid horn antenna was demonstrated as well in the $300-\mathrm{GHz}$ band [131]. Though the details of the structure could not be optimized on the basis of the 


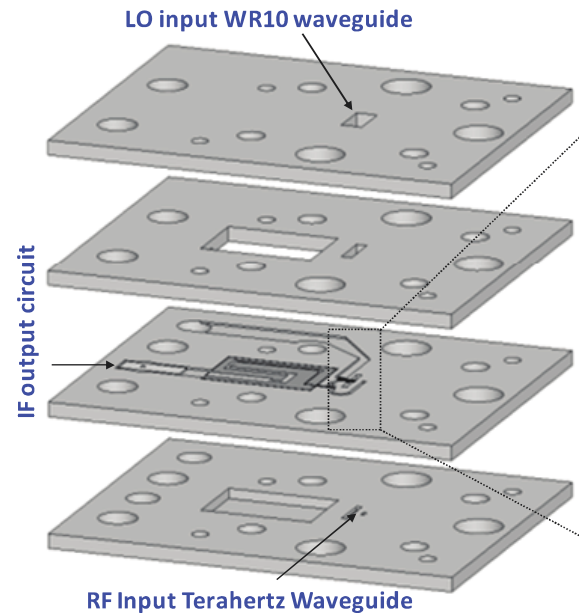

(a)

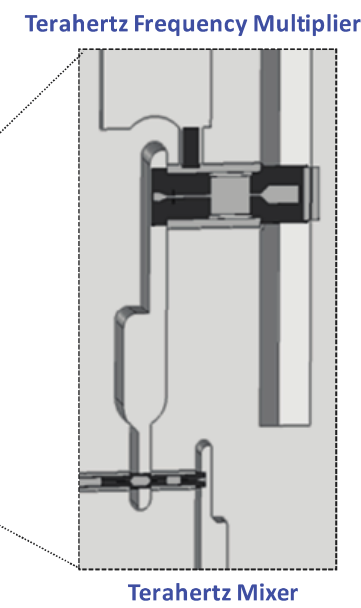

(b)

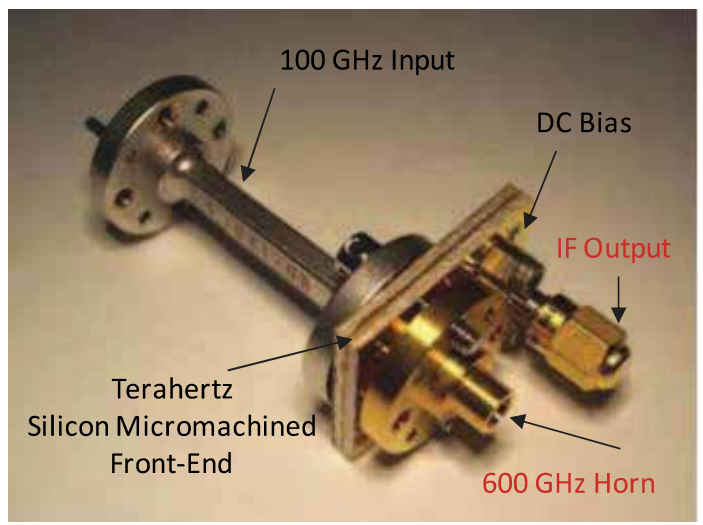

(c)

Fig. 14. Three-dimensional receiver architecture where silicon microhachined wafers are stacked to design the compact receiver front end. (a) Configuration of package with four silicon wafers. (b) Photograph of third layer of package with mixer and frequency multiplier MMICs. (c) Photograph of packaged receiver with metallic WG and horn antenna. Figures from [112].

common design rule [132] due to the limitations in the fabrication, the fabricated antenna (see Fig. 16) yielded promising performance in size and antenna gain. An antenna with an approximately $2.8-\mathrm{mm}$ length was fabricated by stacking 27 LTCC layers, and it exhibited more than 15-dBi gain in the 250-330-GHz band with its peak at $18 \mathrm{dBi}$.

The coupling between the LTCC WG and an MMIC would be achievable with integrated electromagnetic transitions either on the MMICs, as shown in Figs. 10 and 11, or in the package body, as shown in Fig. 15. The latter approach is advantageous for hermetically sealing packages, but with the drawback of transition loss. In [130], a back-to-back microstrip-to-WG transition was experimentally demonstrated. Two WGs were mechanically isolated from each other. In order to enhance the coupling efficiency and bandwidth performance and maintain the hermetic sealing, the dielectric around the electromagnetic couplers was removed and fully dielectric-filled striplines were inserted between the transition probes and MMIC channels as matching circuits. Estimated transition loss per coupler was approximately $1 \mathrm{~dB}$ at $300 \mathrm{GHz}$, which is comparable with that of the integrated transitions on MMICs [97], [103].

We overviewed a few promising results for LTCC technologies at $\mathrm{THz}$ frequencies. Nevertheless, obvious limitations that need to be noted are manufacturing tolerance and large signal loss. The waves in the WG experience the LTCC materials at the corrugations; therefore, the dielectric has a direct impact on the signal loss. In addition, LTCC technologies are generally based on mechanical punching for interlayer vias and thick film patterning for metallization. The stacked base material sheets, commonly called green sheets, are baked at temperatures below $1000{ }^{\circ} \mathrm{C}$, leading to shrinkage of the entire structure. These fabrication processes do not guarantee tolerances as accurate as semiconductor processes do. A quick estimation based on the literature and reports indicates that up to 400-500 GHz would be feasible, if one seeks productivity and ease of manufacturing with moderate performance.

\section{Plastic Molding Technologies}

The plastic injection molding technique is the most popular fabrication technology used in many devices and components in our modern daily lives. Massive-volume production capacity and low component weight are its great advantages over the other fabrication techniques described in previous sections. Unlike silicon micromaching and LTCC fabrication techniques, arbitrary 3-D shapes can be fabricated in a single solid piece of plastic material with quite good accuracy as low as a few micrometers [133]. Since metal can be coated on the plastic surface [134], electrically, the same performance as that for metallic blocks is expected. Unless large power-handling devices are desired, the plastic injection molding technique is another option for $\mathrm{THz}$ packages. In the millimeter-wave band, several WG components, such as antennas, diplexer filters, and hybrid couplers [134]-[136], with reasonable performance have been reported. Crowe et al. reported a 585-GHz Schottky diode mixer module packaged in a metal-coated plastic housing [137]. Once the master blocks had been fabricated with the silicon micromachining process, the mold fixtures were made with the masters. Polyurethane was selected as the molding plastic. According to Crowe et al. [137], the measured performance in an antenna beam pattern and noise temperature was comparable or even better than that of a conventional metallic package module, implying no appreciable problem in the performance with the plastic molding process even at $\mathrm{THz}$ frequencies. 


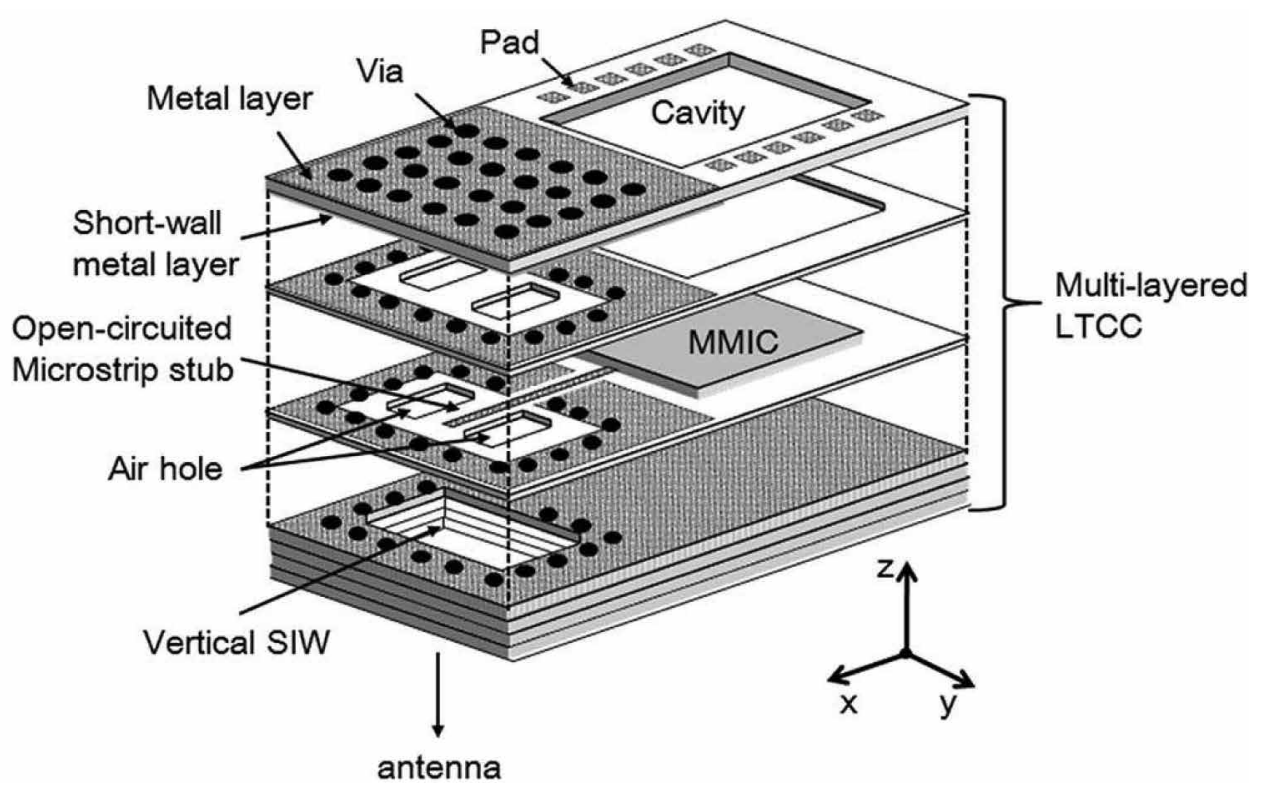

Fig. 15. Concept of LTCC packages for THz MMICs with integrated microstrip-to-waveguide transition in package frame. Figure from [130].

\section{Three-Dimensional Printing Technologies}

Three-dimensional printing has recently been attracting a great deal of interest in prototype manufacturing, not only in production status but also in preliminary development. State-of-the-art printers yield reasonable resolutions for $\mathrm{THz}$ applications: $10-100 \mu \mathrm{m}$ in the XYplane and $30-100 \mu \mathrm{m}$ in the Z-direction. There are various mechanisms for 3-D printing, but we can briefly classify them into the following three [138]: 1) selective deposition of extruded material involving FDM; 2) UV curing of resin, including inkjet printing and SLA technology; and 3) powder binding techniques involving SLS and SLM technologies. At frequencies above $100 \mathrm{GHz}$, SLA and SLM techniques have been rather more commonly used than other techniques because they provide smooth surfaces [138]-[143]. In [138], a W-band WG section was fabricated with an SLA-based printer that is expected to provide approximately $25-\mu \mathrm{m}$ printing resolution. Considering the electroplating for metal coating inside the WG, a split-block structure was used. The measured roughness on the internal surface after the Au-coating was approximately $3 \mu \mathrm{m}$ at peak and $1.16 \mu \mathrm{m}$ in root-meansquare average. The measured insertion loss was approximately $0.011 \mathrm{~dB} / \mathrm{mm}$ at $110 \mathrm{GHz}$, which is comparable with that of the reference metallic WG section. In [144], a Cu-coated WR3.4 WG printed with the same SLA-based printer exhibited $0.012 \sim 0.02-\mathrm{dB} / \mathrm{mm}$ insertion loss in $220-330 \mathrm{GHz}$ (see Fig. 18). In both cases, the values are very close to the theoretical limits, implying quite good mechanical accuracy and surface quality even for THz applications. Although the SLM-based printing technique can directly print a metallic structure, the surface

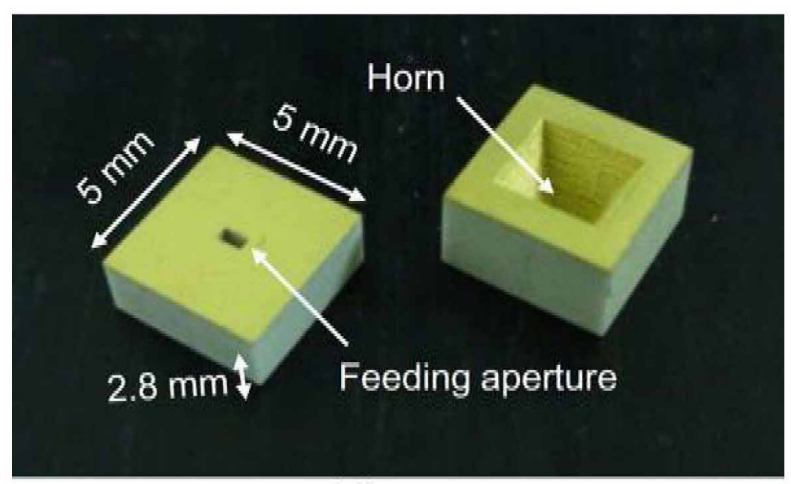

(a)

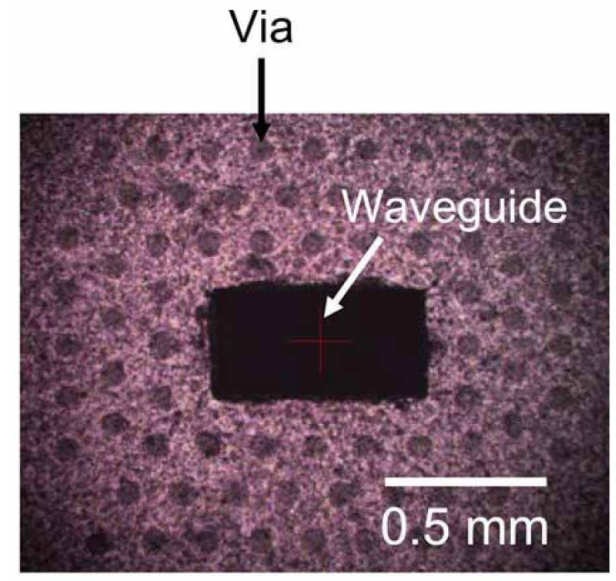

(b)

Fig. 16. (a) Photographe of the fabricated LTCC horn antenna and (b) closeup view of WG interface. Figures from [131]. 


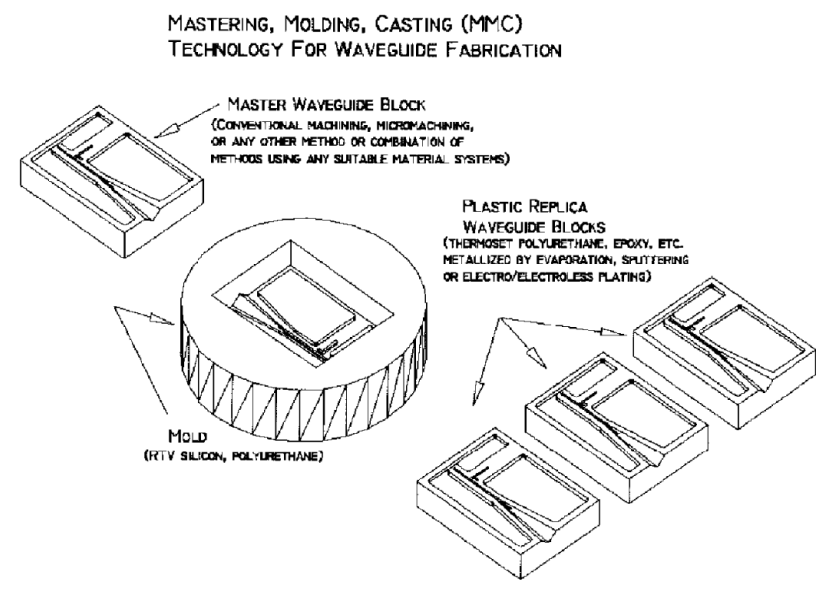

Fig. 17. Molding and casting technique used to replicate inexpensive copies of a THz components [132]. Smooth WG features on the order of hundreds of micrometers have been accurately reproduced and the measured performance for a mold produced mixer block is the same as that for a conventionally machined version. Figure from [107].

can be contaminated with residual metal powder, resulting in degradation of surface smoothness and higher insertion loss [142]. The fabricated SLM WR3.4 WG exhibited approximately $0.09 \sim 0.12 \mathrm{~dB} / \mathrm{mm}$, which could be improved with additional surface treatments.

Unfortunately, so far there have been no reports on $\mathrm{THz}$ packages made with $3-\mathrm{D}$ printing techniques. However, the WG demonstrations above reveal that the surface roughness and dimensional resolution will not be a critical issue up to the 300-400-GHz band. In addition, as the name implies, considering the ease of printing structures with high geometrical complexity, 3-D printing techniques will be suitable tools for rapid prototyping or for small volume production that requires dedicated complicated fabrication steps.

\section{QUASI-OPTICAL PACKAGES}

In many THz applications, including spectroscopy, imaging, and communications, devices and components are actually required to radiate $\mathrm{THz}$ waves into the air or a sample under test and detect the signals that have passed through a certain medium. Therefore, it is natural that $\mathrm{THz}$ packages embed antennas for signal radiation. In the many examples shown in previous sections, horn antennas or radiators were monolithically fabricated with the package body. On the other hand, the antenna or radiators can be integrated into the MMICs or RFICs. In this case, an interconnection for $\mathrm{THz}$ signals will not be necessary in the packages. Fig. 19 shows a conceptual diagram of a quasi-optical $\mathrm{THz}$ package for core devices with an antenna. Imagining packaged optical components such as image sensors and discrete LEDs will help one to have a better understanding of the quasioptical packages. Assuming a transmitter or an emitter, $\mathrm{THz}$ (a)
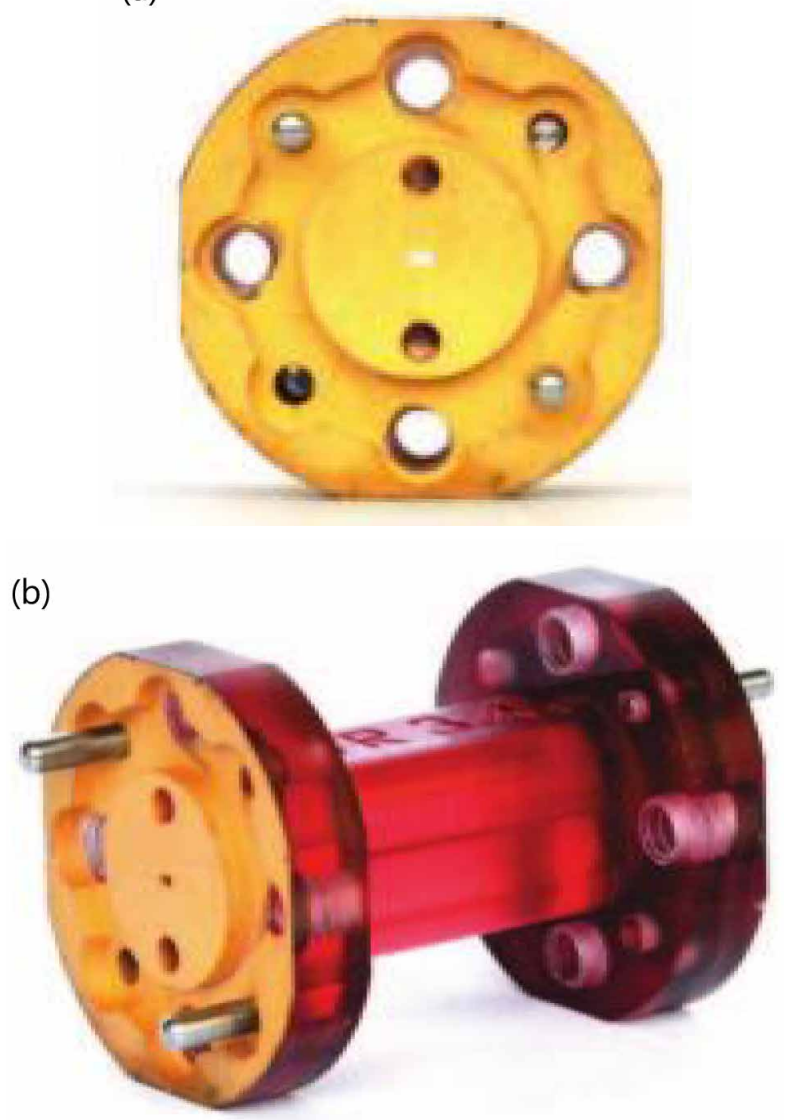

Fig. 18. Phtographs of metal-coated WR3.4 WGs printed with the SLA-based printer. Figures from [144].

waves will be directly radiated into the air from the on-chip antenna. An optical lens would help to improve the directivity of the radiated beam [145]-[148]. Since there is no interconnection for high-frequency signal, the assembly will not be so sensitive to manufacturing tolerances or circuit parasitics.

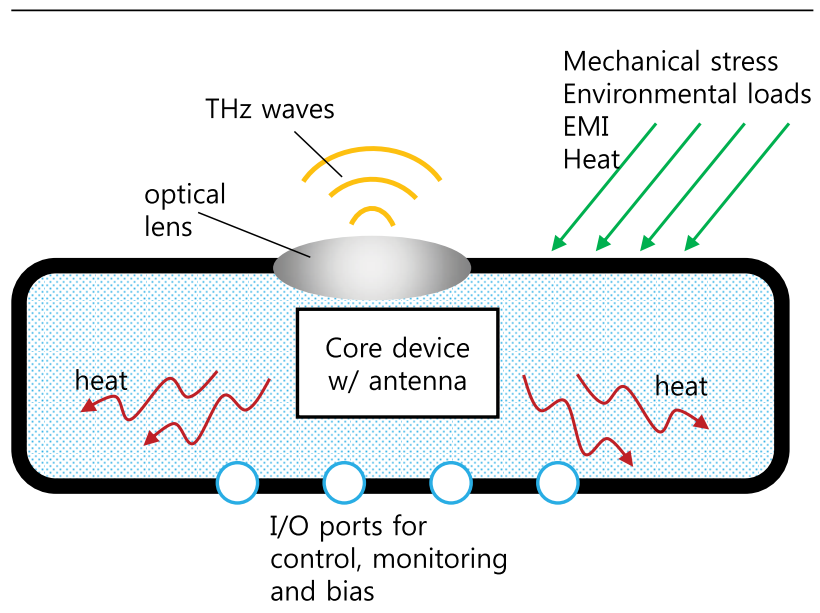

Fig. 19. Conceptual diagram of quasi-optical THz packages. 


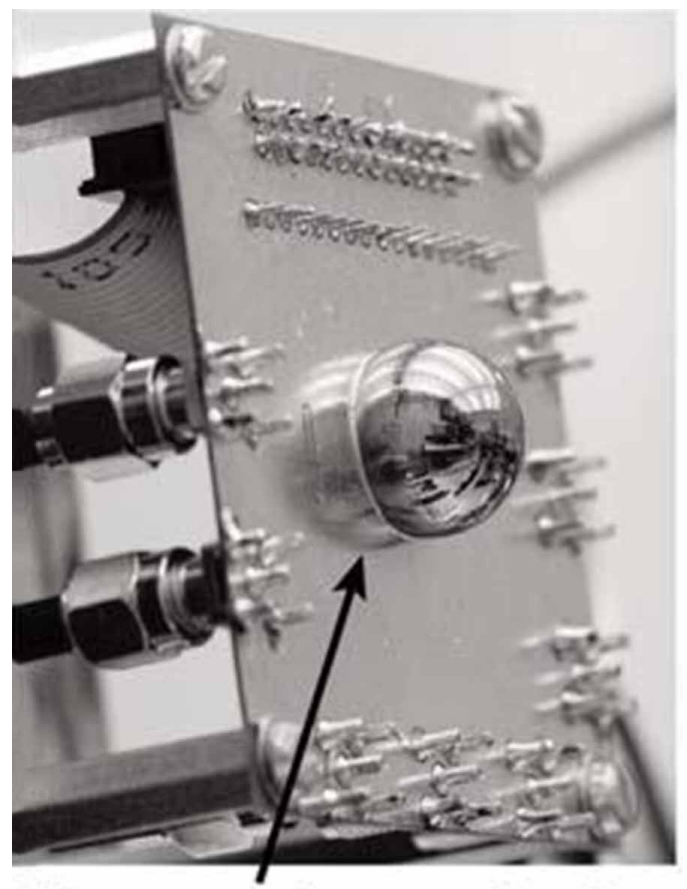

\section{Si Lens mounted on camera board}

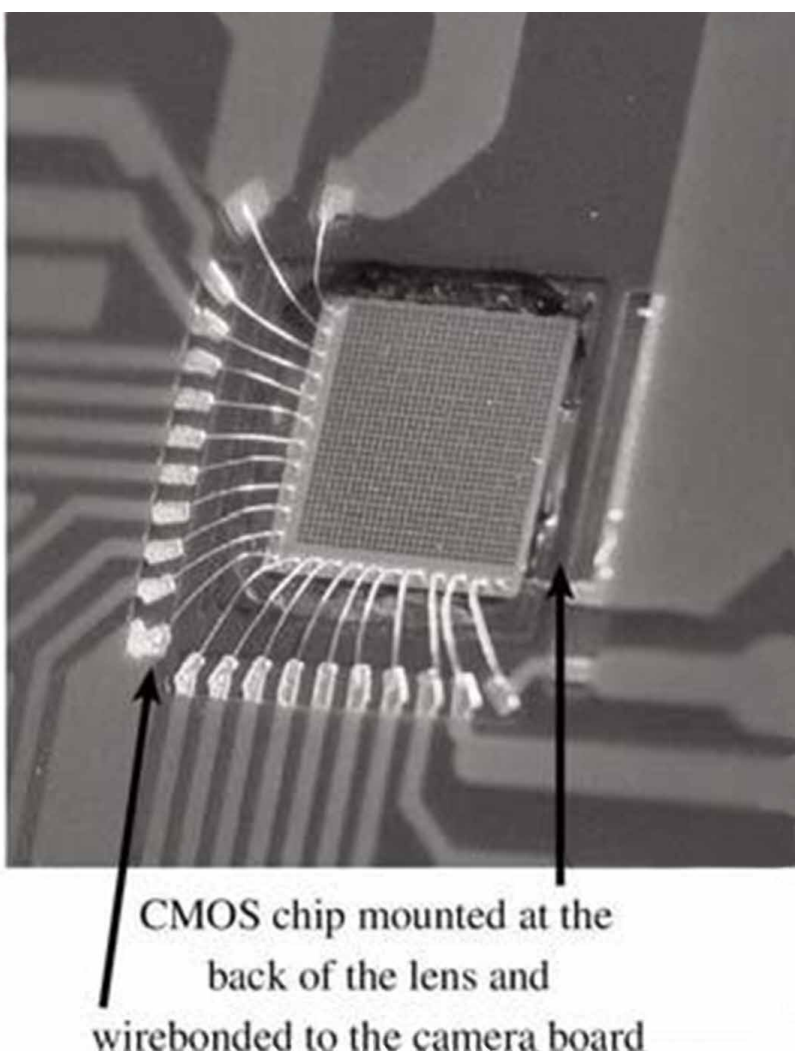

Fig. 20. Photography of packaged THz image sensor with silicon lens. Figure from [145].

Fig. 20 shows a typical example of quasi-optical $\mathrm{THz}$ packages for a $\mathrm{THz}$ image sensor [145]. The image sensor IC with 1-K pixel antennas was mounted on a low-cost printed

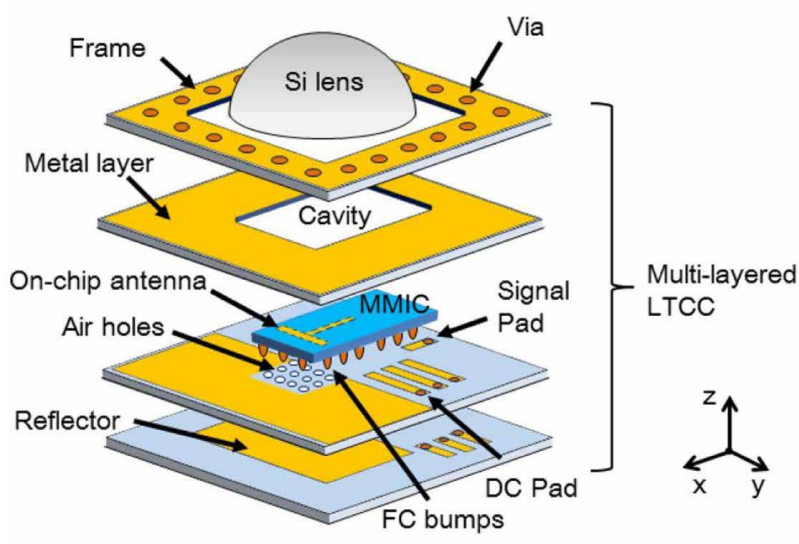

(a)

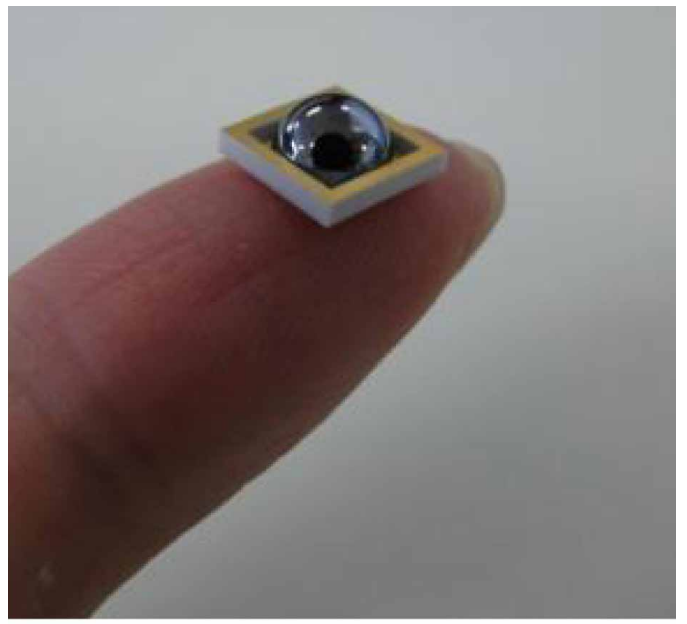

(b)

Fig. 21. (a) Structure of LTCC-based silicon-lens THz package; and (b) photograph of implemented module. Figures from [149].

circuit board (PCB) and wired for dc bias and data readouts. In order to focus the incident $\mathrm{THz}$ waves to the pixel antennas on the IC, a silicon lens was assembled on the backside of the PCB. With advanced manufacturing technology, such a lensed package can be miniaturized by following a concept similar to that for optical components such as LEDs. Fig. 21 shows a compact THz lensed package [149] consisting of an LTCC-based chip carrier, MMIC with an on-chip antenna, and 8-mm-diameter silicon lens. The 300-GHz receiver MMIC for wireless communications [41] was mounted in the LTCC package with a flip-chip bonding technique for dc and data signal readouts, and the silicon lens was placed on the backside of the MMIC and fixed with a nonconductive adhesive epoxy. The performance of the compact module was evaluated in a data transmission experiment and no degradation was observed in the bit error rate and the Q-factor of the recovered eye diagram. 


\section{CONCLUSION}

Recent progress in device technologies, particularly solid-state electronic devices, enables us to generate and detect $\mathrm{THz}$ signals more easily and nicely and to explore what we can do with $\mathrm{THz}$ waves. With the advances in devices, it is envisioned that transmitting huge amounts of data in a second, identifying concealed weapons, diagnosing mutations in biosystems, analyzing molecular structures of chemical materials and many other things will be realized in the near future. On the way toward practical $\mathrm{THz}$ applications, we will face various technical problems associated with interconnections and packaging. As frequency increases, bonding wires cause significant reflection and degradation in signal quality and loss.
Thus, many of the traditional approaches relying on wire bonding are not applicable to $\mathrm{THz}$ applications. Metallic split-block packages with electromagnetic transitions provide excellent performance, but the bulky dimensions and high weight make them unsuitable for applications other than in a couple of limited areas. Micromaching and LTCC technology are capable of implementing the split-block structure for inexpensive and compact packages. Plastic injection molding will yield high productivity, and 3-D printing technologies enable rapid prototyping even for dedicated devices. In addition, taking into account that many $\mathrm{THz}$ applications are expected to work in a quasi-optic operation, lensed packages are potential options, particularly for image sensors and compact radio transceivers.

\section{REFERENCES}

[1] M. F. Kimmitt, "Restrahlen to T-rays100 years of terahertz radiation," J. Biol. Phys., vol. 29, no. 2, pp. 77-85, 2003.

[2] H. Rubens and O. von Baeyer, "On extremely long waves, emitted by the quartz mercury lamp," Philos. Mag., vol. 21, no. 125, pp. 689-695, 1911.

[3] E. F. Nichols and J. D. Tear, "Short electric waves," Phys. Rev., vol. 21, pp. 587-610, Jun. 1923.

[4] A. G. Arkadiewa, "Short electromagnetic waves of wave-length up to $92 \mu$," Nature, vol. 113 , p. $640,1924$.

[5] C. E. Cleeton and N. H. Williams, "Electromagnetic waves of $1.1 \mathrm{~cm}$ wavelength and the absorption spectrum of ammonia," Phys. Rev., vol. 45, pp. 234-237, Feb. 1934.

[6] R. B. Barnes, W. S. Benedict, and C. M. Lewis, "The far infrared spectrum of $\mathrm{H}_{2} \mathrm{O}$," Phys. Rev., vol. 47, no. 12, pp. 918-922, 1935.

[7] H. M. Randall, D. M. Dennison, N. Ginsburg, and L. R. Weber, "The far infrared spectrum of water vapor," Phys. Rev., vol. 52, pp. 160-174, Aug. 1937.

[8] M. J. E. Golay, "A pneumatic infra-red detector," Rev. Sci. Instrum., vol. 18, no. 5, pp. 357-362, 1947.

[9] R. Kompfner and N. T. Williams, "Backwardwave tubes," Proc. IRE, vol. 41, no. 11, pp. 1602-1611, Nov. 1953.

[10] E. H. Putley, "Impurity photoconductivity in n-type InSb," Proc. Phys. Soc., vol. 76, no. 5, pp. 802-805, 1960.

[11] F. J. Low, "Low-temperature germanium bolometer," J. Opt. Soc. Amer., vol. 51, no. 11, pp. 1300-1304, 1961.

[12] E. H. Putley, "Solid state devices for infra-red detection," J. Sci. Instrum., vol. 43, no. 12 pp. 857-868, 1966.

[13] K. Button, Infrared and Millimeter Waves. San Diego, CA, USA: Academic, 1983.

[14] M. van Exter, C. Fattinger, and D. Grischkowsky, "Terahertz time-domain spectroscopy of water vapor," Opt. Lett. vol. 14, no. 20, pp. 1128-1130, 1989.

[15] D. Grischkowsky, S. Keiding, M. van Exter, and C. Fattinger, "Far-infrared time-domain spectroscopy with terahertz beams of dielectrics and semiconductors," J. Opt. Soc. Amer. B, vol. 7, no. 10, pp. 2006-2015, 1990.

[16] M. Tonouchi, "Cutting-edge terahertz technology," Nature Photon., vol. 1, no. 2, pp. 97-105, 2007.

[17] S. L. Dexheimer, Terahertz Spectroscopy: Principles and Applications. Boca Raton, FL, USA: CRC Press, 2007

[18] P. H. Siegel, "Terahertz technology in biology and medicine," in IEEE MTT-S Int. Microw. Symp. Dig., Jun. 2004, pp. 1575-1578.

[19] R. M. Woodward et al., "Terahertz pulse imaging in reflection geometry of human skin cancer and skin tissue," Phys. Med. Biol., vol. 47, no. 21, p. 3853, 2002.

[20] K. Ajito and Y. Ueno, "THz chemical imaging for biological applications," IEEE Trans. THz Sci. Technol., vol. 1, no. 1, pp. 293-300, Sep. 2011.

[21] C. J. Strachan et al., "Using terahertz pulsed spectroscopy to quantify pharmaceutical polymorphism and crystallinity," $J$. Pharmaceutical Sci., vol. 94, no. 4, pp. 837-846, 2005.

[22] D. M. Charron, K. Ajito, J.-Y. Kim, and Y. Ueno, "Chemical mapping of pharmaceutical cocrystals using terahertz spectroscopic imaging," Anal. Chem., vol. 85, no. 4 pp. 1980-1984, 2013

[23] J. F. Federici et al., “THz imaging and sensing for security applications-Explosives, weapons and drugs," Semicond. Sci. Technol., vol. 20, no. 7, p. S266, 2005.

[24] J. Liu, J. Dai, S. L. Chin, and X.-C. Zhang, "Broadband terahertz wave remote sensing using coherent manipulation of fluorescence from asymmetrically ionized gases," Nature Photon., vol. 4, pp. 627-631, Jul. 2010.

[25] D.-H. Kim and J. A. del Alamo, “30 nm E-mode InAs PHEMTs for THz and future logic applications," in Proc. IEEE Int. Electron Devices Meeting, Dec. 2008, pp. 1-4.

[26] J. A. del Alamo, "Nanometre-scale electronics with IIIV compound semiconductors," Nature, vol. 479, pp. 317-323, Nov. 2011.

[27] M. Mikulla et al., "High-speed technologies based on III-V compound semiconductors at Fraunhofer IAF," in Proc. Eur. Microw. Integr. Circuits Conf., 2013, pp. 169-171.

[28] X. Mei et al., "First demonstration of amplification at $1 \mathrm{THz}$ using $25-\mathrm{nm} \mathrm{InP}$ high electron mobility transistor process," IEEE

Electron Device Lett., vol. 36, no. 4 pp. 327-329, Apr. 2015.

[29] T. W. Crowe, W. L. Bishop, D. W. Porterfield, J. L. Hesler, and R. M. Weikle, "Opening the terahertz window with integrated diode circuits," IEEE J. Solid-State Circuits, vol. 40, no. 10, pp. 2104-2110, Oct. 2005.

[30] M. Asada, S. Suzuki, and N. Kishimoto, "Resonant tunneling diodes for sub-terahertz and terahertz oscillators," Jpn. J. Appl. Phys., vol. 47, no. 6R, p. 4375, 2008.

[31] L. Liu, J. L. Hesler, H. Xu, A. W. Lichtenberger, and R. M. Weikle, "A broadband quasi-optical terahertz detector utilizing a zero bias Schottky diode," IEEE Microw. Wireless Compon. Lett., vol. 20, no. 9, pp. 504-506, Sep. 2010.

[32] A. Leuther et al., "35 nm metamorphic HEMT MMIC technology," in Proc. 20th Int. Conf. Indium Phosphide Rel. Mater., 2008, pp. 1-4.

[33] M. Urteaga, R. Pierson, P. Rowell, V. Jain, E. Lobisser, and M. J. W. Rodwell, "130 nm InP DHBTs with $f_{t}>0.52$ THz and $f_{\max }>1.1 \mathrm{THz}$," in Proc. 69th Annu. Device Res. Conf., 2011, pp. 281-282.

[34] L. Samoska, "Towards terahertz MMIC amplifiers: Present status and trends," in IEEE MTT-S Int. Microw. Symp. Dig., Jun. 2006, pp. 333-336.

[35] W. R. Deal et al., "Demonstration of a 0.48 THz amplifier module using InP HEMT transistors," IEEE Microw. Wireless Compon. Lett., vol. 20, no. 5, pp. 289-291, May 2010.

[36] I. Kallfass et al., "All active MMIC-based wireless communication at $220 \mathrm{GHz}$," IEEE Trans. THz Sci. Technol., vol. 1, no. 2, pp. 477-487, Nov. 2011.

[37] V. Radisic, K. M. K. H. Leong, X. Mei, S. Sarkozy, W. Yoshida, and W. R. Deal, "Power amplification at $0.65 \mathrm{THz}$ using INP HEMTs," IEEE Trans. Microw. Theory Techn., vol. 60, no. 3, pp. 724-729, Mar. 2012.

[38] E. Seok et al., "Progress and challenges towards terahertz CMOS integrated circuits," IEEE J. Solid-State Circuits, vol. 45, no. 8, pp. 1554-1564, Aug. 2010.

[39] O. Momeni and E. Afshari, "High power terahertz and millimeter-wave oscillator design: A systematic approach," IEEE J. Solid-State Circuits, vol. 46, no. 3, pp. 583-597, Mar. 2011. 
[40] J.-Y. Kim, H.-J. Song, K. Ajito, M. Yaita, and N. Kukutsu, "A $325 \mathrm{GHz}$ quadrature voltage controlled oscillator with superharmonic-coupling," IEEE Microw. Wireless Compon. Lett., vol. 23, no. 8, pp. 430-432, Aug. 2013.

[41] H.-J. Song, J.-Y. Kim, K. Ajito, M. Yaita, and N. Kukutsu, "Fully integrated ASK receiver MMIC for terahertz communications at 300 GHz," IEEE Trans. THz Sci. Technol., vol. 3, no. 4, pp. 445-452, Jul. 2013.

[42] H.-J. Song, J.-Y. Kim, K. Ajito, N. Kukutsu, and M. Yaita, "50-Gb/s direct conversion QPSK modulator and demodulator MMICs for terahertz communications at $300 \mathrm{GHz}$," IEEE Trans. Microw. Theory Techn., vol. 62, no. 3, pp. 600-609, Mar. 2014.

[43] H. Hamada et al., "300-GHz band 20-Gbps ASK transmitter module based on InP-HEMT MMICs," in Proc. IEEE Compound Semicond. Integr. Circuit Symp., Oct. 2015, pp. 1-4.

[44] M. Seo, M. Urteaga, M. Rodwell, and M.-J. Choe, "A 300 GHz PLL in an InP HBT technology," in IEEE MTT-S Int. Microw. Symp. Dig., Jun. 2011, pp. 1-4.

[45] M. Seo et al., "A single-chip $630 \mathrm{GHz}$ transmitter with $210 \mathrm{GHz}$ sub-harmonic PLL local oscillator in $130 \mathrm{~nm}$ InP HBT," in IEEE MTT-S Int. Microw. Symp. Dig., Jun. 2012, pp. 1-3.

[46] R. Al Hadi et al., "A 1 k-pixel video camera for 0.71 .1 terahertz imaging applications in 65-nm CMOS," IEEE J. Solid-State Circuits, vol. 47, no. 12, pp. 2999-3012, Dec. 2012.

[47] H.-J. Song and T. Nagatsuma, "Present and future of terahertz communications," IEEE Trans. THz Sci. Technol., vol. 1, no. 1, pp. 256-263, Sep. 2011.

[48] K. B. Cooper et al., "Fast high-resolution terahertz radar imaging at 25 meters," Proc. SPIE, vol. 7671, pp. 76710Y-1-76710Y-8, Apr. 2010.

[49] H.-J. Song et al., "Demonstration of 20-Gbps wireless data transmission at $300 \mathrm{GHz}$ for KIOSK instant data downloading applications with InP MMICs," in IEEE MTT-S Int. Microw. Symp. Dig., San Francisco, CA, USA, May 2016, pp. 1-4, paper WEIF2-29.

[50] L. Devlin, "The future of mm-wave packaging," Microw. J., vol. 57, p. 24, Feb. 2014.

[51] W. Menzel, "Packaging and interconnects for millimeter wave circuits: A review," Ann. Tlcommun., vol. 52, no. 3, pp. 145-154, 1997.

[52] U. Pfeiffer, "Millimeter-wave packaging," in Advanced Millimeter-Wave Technologies, D. Liu, B. Gaucher, U. Pfeiffer, and J. Grzyb, Eds. Chichester, U.K.: Wiley, 2009, pp. 15-48.

[53] J.-Y. Kim, H.-Y. Lee, J.-H. Lee, and D.-P. Chang, "Wideband characterization of multiple bondwires for millimeter-wave applications," in Proc. Asia-Pacific Microw. Conf., 2000, pp. 1265-1268.

[54] Keysight Technologies, Coaxial Connector Overview-Technical Overview,2014. [Online]. Available: http://literature.cdn.keysight.com/ litweb/pdf/5992-0118EN.pdf?id=2515539

[55] Keysight Technologies, Coaxial Systems: Principles of Microwave Connector Care (AN 326), 1988. [Online]. Available: http:// literature.cdn.keysight.com/litweb/pdf/59541566.pdf?id $=1329068$

[56] P. F. Goldsmith, Quasioptical Systems, 1st ed. Hoboken, NJ, USA: Wiley, 1998.

[57] L. Duvillaret, F. Garet, and J.-L. Coutaz, "Highly precise determination of optical constants and sample thickness in terahertz time-domain spectroscopy," Appl. Opt., vol. 38, no. 2, pp. 409-415, 1999.
[58] L. Duvillaret, F. Garet, and J.-L. Coutaz, "Influence of noise on the characterization of materials by terahertz time-domain spectroscopy," J. Opt. Soc. Amer. B, vol. 17, no. 3, pp. 452-461, 2000.

[59] G. Zhao, M. ter Mors, T. Wenckebach, and P. C. M. Planken, "Terahertz dielectric properties of polystyrene foam," J. Opt. Soc. Amer. B, vol. 19, no. 6, pp. 1476-1479, 2002.

[60] P. H. Bolivar et al., "Measurement of the dielectric constant and loss tangent of high dielectric-constant materials at terahertz frequencies," IEEE Trans. Microw. Theory Techn., vol. 51, no. 4, pp. 1062-1066, Apr. 2003.

[61] C. Roman, O. Ichim, L. Sarger, V. Vigneras, and P. Mounaix, "Terahertz dielectric characterisation of polymethacrylimide rigid foam: The perfect sheer plate?" Electron. Lett., vol. 40, no. 19, pp. 1167-1169, Sep. 2004.

[62] Y.-S. Jin, G.-J. Kim, and S.-G. Jeon, "Terahertz dielectric properties of polymers," J. Korean Phys. Soc., vol. 49, no. 2, pp. 513517, 2006.

[63] E. Perret, N. Zerounian, S. David, and F. Aniel, "Complex permittivity characterization of benzocyclobutene for terahertz applications," Microelectron. Eng., vol. 85, pp. 2276-2281, Nov. 2008.

[64] A. Younus, P. Desbarats, S. Bosio, E. Abraham, J. C. Delagnes, and P. Mounaix, "Terahertz dielectric characterisation of photopolymer resin used for fabrication of 3D THz imaging phantoms," Electron. Lett., vol. 45, no. 13, pp. 702-703, 2009.

[65] J. A. Hejase, P. R. Paladhi, and P. P. Chahal, "Terahertz characterization of dielectric substrates for component design and nondestructive evaluation of packages," IEEE Trans. Compon. Packag. Manuf. Technol., vol. 1, no. 11, pp. 1685-1694, Nov. 2011.

[66] T. D. Dorney, R. G. Baraniuk, and D. M. Mittleman, "Material parameter estimation with terahertz time-domain spectroscopy," J. Opt. Soc. Amer. A, vol. 18, pp. 1562-1571, Jul. 2001.

[67] M. Naftaly and R. E. Miles, "Terahertz timedomain spectroscopy for material characterization," Proc. IEEE, vol. 95, no. 8, pp. 1658-1665, Aug. 2007.

[68] A. Podzorov and G. Gallot, "Low-loss polymers for terahertz applications," Appl. Opt., vol. 47, no. 18, pp. 3254-3257, 2008.

[69] F. Alimenti, P. Mezzanotte, L. Roselli, and R. Sorrentino, "Modeling and characterization of the bonding-wire interconnection," IEEE Trans. Microw. Theory Techn., vol. 49, no. 1, pp. 142-150, Jan. 2001.

[70] A. Sutono, N. G. Cafaro, J. Laskar, and M. M. Tentzeris, "Experimental modeling, repeatability investigation and optimization of microwave bond wire interconnects," IEEE Trans. Adv. Packag., vol. 24, no. 4, pp. 595-603, Nov. 2001.

[71] P. Huang, R. Lai, R. Grundbacher, and B. Gorospe, "A 20-mW G-band monolithic driver amplifier using 0.07- $\mu \mathrm{m}$ InP HEMT," in IEEE MTT-S Int. Microw. Symp. Dig., Jun. 2006, pp. 806-809.

[72] H. J. Song, K. Ajito, Y. Muramoto, A. Wakatsuki, T. Nagatsuma, and N. Kukutsu, "Uni-travelling-carrier photodiode module generating $300 \mathrm{GHz}$ power greater than 1 mW," IEEE Microw. Wireless Compon. Lett., vol. 22, no. 7, pp. 363-365, Jul. 2012.

[73] A. Tessmann et al., "A 300 GHz mHEMT amplifier module," in Proc. IEEE Int. Conf.
Indium Phosphide Rel. Mater. (IPRM), May 2009, pp. 196-199.

[74] T. Kosugi et al., " $250300 \mathrm{GHz}$ waveguide module with ridge-coupler and InPHEMTIC," in Proc. Asia-Pacific Microw. Conf., 2014, pp. 1133-1135.

[75] W. Heinrich, "The flip-chip approach for millimeter wave packaging," IEEE Microw. Mag., vol. 6, no. 3, pp. 36-45, Sep. 2005.

[76] S. Monayakul et al., "Flip-chip interconnects for $250 \mathrm{GHz}$ modules," IEEE Microw. Wireless Compon. Lett., vol. 25, no. 6, pp. 358-360, Jun. 2015.

[77] Y. Kawano et al., "Flip chip assembly for submillimeter wave amplifier MMIC on polyimide substrate," in IEEE MTT-S Int. Microw. Symp. Dig., Jun. 2014, pp. 1-4.

[78] A. Jentzsch and W. Heinrich, "Theory and measurements of flip-chip interconnects for frequencies up to $100 \mathrm{GHz}$," IEEE Trans. Microw. Theory Techn., vol. 49, no. 5, pp. 871-878, May 2001.

[79] J. Grzyb, Millimeter-wave interconnects, in "Advanced Millimeter-Wave Technologies," D. Liu, B. Gaucher, U. Pfeiffer, and J. Grzyb, Eds. London, U.K.: Wiley, 2009, pp. 71-161.

[80] J. H. Booske, "Plasma physics and related challenges of millimeter-wave-to-terahertz and high power microwave generation," Phys. Plasmas, vol. 15, no. 5, p. 055502, 2008.

[81] N. Ridler and R. Ginley, "IEEE P1785: A new standard for waveguide above $110 \mathrm{GHz}$," Microw. J., vol. 54, no. 3, pp. 20-24, 2011.

[82] A. R. Kerr, E. Wollack, and N. Horner, "Waveguide flanges for ALMA instrumentation," ALMA Memo, vol. 278, 1999.

[83] S. Martin et al., "Fabrication of 200 to 2700 GHz multiplier devices using GaAs and metal membranes," in IEEE MTT-S Int. Microw. Symp. Dig., vol. 3. May 2001, pp. 1641-1644.

[84] E. Schlecht et al., "200, 400 and $800 \mathrm{GHz}$ Schottky diode substrateless multipliers: Design and results," in IEEE MTT-S Int. Microw. Symp. Dig., vol. 3. May 2001, pp. 1649-1652.

[85] G. Chattopadhyay et al., "A broadband 800 GHz Schottky balanced doubler," IEEE Microw. Wireless Compon. Lett., vol. 12, no. 4, pp. 117-118, Apr. 2002.

[86] G. Chattopadhyay et al., "An all-solid-state broad-band frequency multiplier chain at 1500 GHz," IEEE Trans. Microw. Theory Techn., vol. 52, no. 5, pp. 1538-1547, May 2004.

[87] A. Maestrini et al., "A 1.71.9 THz local oscillator source," IEEE Microw. Wireless Compon. Lett., vol. 14, no. 6, pp. 253-255, Jun. 2004.

[88] A. Maestrini et al., "A 540640-GHz highefficiency four-anode frequency tripler," IEEE Trans. Microw. Theory Techn., vol. 53, no. 9, pp. 2835-2843, Sep. 2005.

[89] B. Thomas et al., "A $530600 \mathrm{GHz}$ silicon micro-machined integrated receiver using GaAs MMIC membrane planar Schottky diodes," in Proc. 21st Int. Symp. Space Terahertz Technol., Oxford, U.K., 2010, pp. 161-164.

[90] D. Dochev, V. Desmaris, D. Meledin, A. Pavolotsky, and V. Belitsky, "A technology demonstrator for 1.62.0 THz waveguide HEB receiver with a novel mixer layout," J. Infr. Millimeter Terahertz Waves, vol. 32, no. 4, pp. 451-465, Apr. 2011. 
[91] A. Maestrini et al., "A frequency-multiplied source with more than $1 \mathrm{~mW}$ of power across the 840900-GHz band," IEEE Trans. Microw. Theory Techn., vol. 58, no. 7, pp. 1925-1932, Jul. 2010.

[92] A. Maestrini et al., "Design and characterization of a room temperature allsolid-state electronic source tunable from 2.48 to $2.75 \mathrm{THz}$," IEEE Trans. THz Sci. Technol., vol. 2, no. 2, pp. 177-185, Mar. 2012.

[93] G. Chattopadhyay, "Technology, capabilities, and performance of low power terahertz sources," IEEE Trans. THz Sci. Technol., vol. 1, no. 1, pp. 33-53, Sep. 2011.

[94] L. Samoska et al., "A submillimeter-wave HEMT amplifier module with integrated waveguide transitions operating above 300 GHz," IEEE Trans. Microw. Theory Techn., vol. 56, no. 6, pp. 1380-1388, Jun. 2008.

[95] V. Radisic et al., "A 10-mW submillimeterwave solid-state power-amplifier module," IEEE Trans. Microw. Theory Techn., vol. 58, no. 7, pp. 1903-1909, Jul. 2010.

[96] V. Radisic et al., "220-GHz solid-state power amplifier modules," IEEE J. Solid-State Circuits, vol. 47, no. 10, pp. 2291-2297, Oct. 2012.

[97] K. M. K. H. Leong et al., "A $340380 \mathrm{GHz}$ integrated CB-CPW-to-waveguide transition for sub millimeter-wave MMIC packaging," IEEE Microw. Wireless Compon. Lett., vol. 19, no. 6, pp. 413-415, Jun. 2009.

[98] K. Leong et al., "Progress in InP HEMT submillimeter wave circuits and packaging," in Proc. IEEE Compound Semicond. Integr. Circuit Symp., Oct. 2015, pp. 1-4.

[99] M. Urteaga et al., "InP HBT integrated circuit technology for terahertz frequencies," in Proc. IEEE Compound Semicond. Integr. Circuit Symp., Oct. 2010, pp. 1-4.

[100] A. Tessmann et al., "Metamorphic HEMT MMICs and modules operating between 300 and $500 \mathrm{GHz}$," IEEE J. Solid-State Circuits, vol. 46, no. 10, pp. 2193-2202, Oct. 2011.

[101] A. Tessmann et al., " $243 \mathrm{GHz}$ low-noise amplifier MMICs and modules based on metamorphic HEMT technology," Int. J. Microw. Wireless Technol., vol. 6, pp. 215-223, Jun. 2014.

[102] V. Hurm et al., "A $243 \mathrm{GHz}$ LNA module based on mHEMT MMICs with integrated waveguide transitions," IEEE Microw. Wireless Compon. Lett., vol. 23, no. 9, pp. 486-488, Sep. 2013.

[103] H. J. Song, H. Matsuzaki, and M. Yaita, "Sub-millimeter and terahertz-wave packaging for large chip-width MMICs," IEEE Microw. Wireless Compon. Lett., vol. 26, no. 6, pp. 422-424, Jun. 2016.

[104] D. Rutledge, S. Schwarz, T. L. Hwang, D. Angelakos, K. Mei, and S. Yokota, "Antennas and waveguides for far-infrared integrated circuits," IEEE J. Quantum Electron., vol. 16, no. 5, pp. 508-516, May 1980.

[105] P. L. Kirby, D. Pukala, H. Manohara, I. Mehdi, and J. Papapolymerou, "Characterization of micromachined silicon rectangular waveguide at $400 \mathrm{GHz}$," IEEE Microw. Wireless Compon. Lett., vol. 16, no. 6, pp. 366-368, Jun. 2006.

[106] K. E. Petersen, "Silicon as a mechanical material," Proc. IEEE, vol. 70, no. 5, pp. 420-457, May 1982.

[107] V. M. Lubecke, K. Mizuno, and G. M. Rebeiz, "Micromachining for terahertz applications," IEEE Trans. Microw. Theory Techn., vol. 46, no. 11, pp. 1821-1831, Nov. 1998.

[108] C. Jung et al., "Silicon micromachining technology for THz applications," in Proc. 35th Int. Conf. Infr. Millimeter Terahertz Waves, 2010, pp. 1-3.

[109] K. M. K. H. Leong et al., "WR1.5 silicon micromachined waveguide components and active circuit integration methodology," IEEE Trans. Microw. Theory Techn., vol. 60, no. 4, pp. 998-1005, Apr. 2012.

[110] C. Jung et al., "Compact submillimeterwave receivers made with semiconductor nano-fabrication technologies," in IEEE MTT-S Int. Microw. Symp. Dig., Jun. 2011, pp. 1-4.

[111] T. J. Reck, C. Jung-Kubiak, J. Gill, and G. Chattopadhyay, "Measurement of silicon micromachined waveguide components at $500750 \mathrm{GHz}$," IEEE Trans. THz Sci. Technol., vol. 4, no. 1, pp. 33-38, Jan. 2014.

[112] G. Chattopadhayay et al., "Integrated arrays on silicon at terahertz frequencies," in Proc. IEEE Int. Symp. Antennas Propag., Jul. 2011, pp. 3007-3010.

[113] K. Konstantinidis, A. P. Feresidis, Y. T. Tian, X. B. Shang, and M. J. Lancaster "Micromachined terahertz FabryPerot cavity highly directive antennas," IET Microw. Antennas Propag., vol. 9, no. 13, pp. 1436-1443, Oct. 2015

[114] C. Lee et al., "Terahertz antenna arrays with silicon micromachined-based microlens antenna and corrugated horns," in Proc. Int. Workshop Antenna Technol. (iWAT), Mar. 2015, pp. 70-73.

[115] S. Liu et al., "Silicon micromachined waveguide quadrature-hybrid coupler at terahertz frequency band," J. Infr. Millimeter Terahertz Waves, vol. 36, no. 8, pp. 709-719, 2015.

[116] C. A. Leal-Sevillano, Y. Tian, M. J. Lancaster, J. A. Ruiz-Cruz, J. R. MontejoGarai, and J. M. Rebollar, "A micromachined dual-band orthomode transducer," IEEE Trans. Microw. Theory Techn., vol. 62, no. 1, pp. 55-63, Jan. 2014.

[117] Z. Zheng, J. Hu, S. Liu, and Y. Zhang, "WR1.5 band waveguide bandpass dual-mode filter on silicon micromachining technique," in Proc. IEEE Int. Conf. Commun. Problem-Solving, Oct. 2015, pp. 112-114.

[118] P. L. Kirby, D. Pukala, H. Manohara, I. Mehdi, and J. Papapolymerou, "A micromachined $400 \mathrm{GHz}$ rectangular waveguide and 3-pole bandpass filter on a silicon substrate," in IEEE MTT-S Int. Microw. Symp. Dig., Jun. 2004, pp. 1185-1188.

[119] K. Hui, J. L. Hesler, D. S. Kurtz, W. L. Bishop, and T. W. Crowe, "A micromachined 585 GHz Schottky mixer," IEEE Microw. Guided Wave Lett., vol. 10, no. 9, pp. 374-376, Sep. 2000.

[120] J. V. Siles et al., "A dual-output $550 \mathrm{GHz}$ frequency tripler featuring ultra-compact silicon micromachining packaging and enhanced power-handling capabilities," in Proc. Eur. Microw. Conf., Sep. 2015, pp. $845-848$.

[121] T. Reck et al., "A silicon micromachined eightpixel transceiver array for submillimeterwave radar," IEEE Trans. THz Sci. Technol., vol. 5, no. 2, pp. 197-206, Mar. 2015.

[122] V. Desmaris, D. Meledin, A. Pavolotsky, R. Monje, and V. Belitsky, "All-metal micromachining for the fabrication of submillimetre and $\mathrm{THz}$ waveguide components and circuits," J. Micromech. Microeng., vol. 18, no. 9, p. 095004, 2008.

[123] A. E. I. Lamminen, J. Saily, and A. R. Vimpari, "60-GHz patch antennas and arrays on LTCC with embedded-cavity substrates," IEEE Trans. Antennas Propag., vol. 56, no. 9, pp. 2865-2874, Sep. 2008.

[124] J. Xu, Z. N. Chen, X. Qing, and W. Hong, "Bandwidth enhancement for a $60 \mathrm{GHz}$ substrate integrated waveguide fed cavity array antenna on LTCC," IEEE Trans. Antennas Propag., vol. 59, no. 3, pp. 826-832, Mar. 2011.

[125] H. Li, W. Hong, T. J. Cui, K. Wu, Y. L. Zhang, and L. Yan, "Propagation characteristics of substrate integrated waveguide based on LTCC," in IEEE MTT-S Int. Microw. Symp. Dig., Jun. 2003, pp. 2045-2048.

[126] H. Y. Chien, T. M. Shen, T. Y. Huang, W. H. Wang, and R. B. Wu, "Miniaturized bandpass filters with double-folded substrate integrated waveguide resonators in LTCC," IEEE Trans. Microw. Theory Techn., vol. 57, no. 7, pp. 1774-1782, Jul. 2009.

[127] Y. P. Zhang, M. Sun, K. M. Chua, L. L. Wai, D. Liu, and B. P. Gaucher, "Antenna-inpackage in LTCC for 60-GHz radio," in Proc. Int. Workshop Antenna Technol., Small Smart Antennas Metamater. Appl., Mar. 2007, pp. 279-282.

[128] Y. P. Zhang, M. Sun, K. M. Chua, L. L. Wai, and D. X. Liu, "Integration of slot antenna in LTCC package for $60 \mathrm{GHz}$ radios," Electron. Lett., vol. 44, no. 5, pp. 330-331, Feb. 2008.

[129] W. Hong, A. Goudelev, K.-H. Baek, V. Arkhipenkov, and J. Lee, "24-element antenna-in-package for stationary $60-\mathrm{GHz}$ communication scenarios," IEEE Antennas Wireless Propag. Lett., vol. 10, pp. 738-741, 2011.

[130] T. Tajima, H.-J. Song, and M. Yaita, “Design and analysis of LTCC-integrated planar microstrip-to-waveguide transition at 300 GHz," IEEE Trans. Microw. Theory Techn., vol. 64, no. 1, pp. 106-114, Jan. 2016.

[131] T. Tajima, H.-J. Song, K. Ajito, M. Yaita, and N. Kukutsu, "300-GHz step-profiled corrugated horn antennas integrated in LTCC," IEEE Trans. Antennas Propag., vol. 62, no. 11, pp. 5437-5444, Nov. 2014.

[132] A. P. King, "The radiation characteristics of conical horn antennas," Proc. IRE, vol. 38, no. 3, pp. 249-251, Mar. 1950.

[133] R. Ruprecht, T. Gietzelt, K. Mller, V. Piotter, and J. Hauelt, "Injection molding of microstructured components from plastics, metals and ceramics," Microsyst. Technol., vol. 8, no. 4, pp. 351-358, Aug. 2002.

[134] M. Wagner, D. Stanelli, P. Nuechter, and U. Goebel, "Compact $60 \mathrm{GHz}$ diplexer in metallized plastic technology for gigabit wireless links," in Proc. 34th Eur. Microw. Conf., Oct. 2004, pp. 1009-1012.

[135] K. Sakakibara, T. Watanabe, K. Nishikawa, and K. Seo, "Millimeter-wave slotted waveguide array antenna manufactured by metal injection molding for automotive radar systems," IEICE Trans. Commun., vol. 84, no. 9, pp. 2369-2376, 2001.

[136] H. Asao, K. Henmi, M. Mukuda, and N. Yoneda, "Ku-band power combiner composed of metal-plated plastic waveguide hybrid," in IEEE MTT-S Int. Microw. Symp. Dig., Jun. 2004, pp. 625-628. 
[137] T. W. Crowe et al., "Inexpensive receiver components for millimeter and submillimeter wavelengths," in Proc. 8th Int. Symp. Space THz Technol., Cambridge, MA, USA, Mar. 1997, pp. 377-384.

[138] M. DAuria et al., "3-D printed metal-pipe rectangular waveguides," IEEE Trans. Compon., Packag., Manuf. Technol., vol. 5, no. 9, pp. 1339-1349, Sep. 2015.

[139] A. Macor, E. de Rijk, S. Alberti, T. Goodman, and J.-P. Ansermet, "Note: Three-dimensional stereolithography for millimeter wave and terahertz applications," Rev. Sci. Instrum., vol. 83, no. 4, p. 046103, 2012.

[140] P. Nayeri et al., "3D printed dielectric reflectarrays: Low-cost high-gain antennas at sub-millimeter waves," IEEE Trans. Antennas Propag., vol. 62, no. 4, pp. 20002008, Apr. 2014.

[141] A. Kaur, J. C. Myers, M. I. M. Ghazali, J. Byford, and P. Chahal, "Affordable terahertz components using 3D printing," in Proc. IEEE 65th Electron.
Compon. Technol. Conf., May 2015, pp. 2071-2076.

[142] B. Zhang and H. Zirath, "Metallic 3-D printed rectangular waveguides for millimeter-wave applications," IEEE Trans. Compon. Packag. Manuf. Technol., vol. 6, no. 5, pp. 796-804, May 2016.

[143] B. Zhang et al., "Metallic 3-D printed antennas for millimeter- and submillimeter wave applications," IEEE Trans. THz Sci. Technol., vol. 6, no. 4 pp. 592-600, Jul. 2016.

[144] A. von Bieren, E. de Rijk, J.-P. Ansermet, and A. Macor, "Monolithic metal-coated plastic components for $\mathrm{mm}$-wave applications," in Proc. 39th Int. Conf. Infr., Millimeter Terahertz Waves, Sep. 2014 pp. 1-2.

[145] H. Sherry et al., "A 1kpixel CMOS camera chip for 25fps real-time terahertz imaging applications," in Proc. IEEE Int. Solid-State Circuits Conf., Feb. 2012, pp. 252-254.
[146] J. Grzyb, Y. Zhao, and U. R. Pfeiffer, “A 288$\mathrm{GHz}$ lens-integrated balanced triple-push source in a 65-nm CMOS technology," IEEE J. Solid-State Circuits, vol. 48, no. 7, pp. 1751-1761, Jul. 2013.

[147] R. Han and E. Afshari, "A 260GHz broadband source with $1.1 \mathrm{~mW}$ continuouswave radiated power and EIRP of $15.7 \mathrm{dBm}$ in 65nm CMOS," in IEEE Int. Solid-State Circuits Conf. (ISSCC) Dig. Tech. Papers, Feb. 2013, pp. 138-139.

[148] U. R. Pfeiffer et al., "A $0.53 \mathrm{THz}$ reconfigurable source array with up to $1 \mathrm{~mW}$ radiated power for terahertz imaging applications in $0.13 \mu \mathrm{m} \mathrm{SiGe}$ BiCMOS," in IEEE Int. Solid-State Circuits Conf. (ISSCC) Dig. Tech. Papers, Feb. 2014, pp. 256-257.

[149] T. Tajima, H.-J. Song, and M. Yaita, "Compact THz LTCC receiver module for $300 \mathrm{GHz}$ wireless communications," IEEE Microw. Wireless Compon. Lett., vol. 26, no. 4, pp. 291-293, Apr. 2016.

\section{ABOUT THE AUTHORS}

Ho-Jin Song (Senior Member, IEEE) received the M.S. and Ph.D. degrees in electronics engineering from Gwangju Institute of Science and Technology (GIST), Gwangju, South Korea, in 2001, and 2005, respectively.

From 2005 to 2006, he was with the Center for Hybrid Optical Access Networks (CHOAN), GIST, as a Research Professor, and was engaged in research on radio-over-fiber technologies cooperating with the Local Multipoint Distribu-

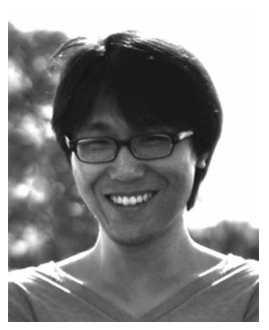
tion Service (LMDS) wireless systems operating at 26 and $28 \mathrm{GHz}$. Since he joined NTT Microsystem Integration Laboratories, Nippon Telegraph and Telephone Corporation (NTT), Atsugi, Kanagawa, Japan, in 2006, he has been working on the development of millimeter-wave and subterahertz wave systems for communications, sensing, imaging, radar, and measurement applications operating at above $100 \mathrm{GHz}$ utilizing both high-speed electronic and photonic technologies. In 2015, he was named a Distinguished Research Scientist of NTT Laboratories. Since 2016 , he has been an Associate Professor of Electrical Engineering at Pohang University of Science and Technology (POSTECH), Pohang, Gyeongbuk, South Korea. He has more than 100 peer-reviewed international journal and conference publications in mm/THz-wave ICs, microwavephotonics, and the system demonstrations. He also holds more than 20 patents filed in Japan and Korea. His current research area covers millimeter and terahertz ICs based on InP, SiGe, and Si-CMOS electronics, their packaging technologies, novel terahertz metamaterial components and photonic integrated circuits with silicon photonic technologies for wireless communications, sensing, radar and bioimaging applications. In addition, he is also interested in wireless front-haul network systems and millimeter-wave RF front-ends for the $5 \mathrm{G}$ massive MIMO systems.

Prof. Song was awarded the Best Thesis Award from the Gwangju Institute of Science and Technology (2005), the Young Scientist Award of the Spectroscopical Society of Japan (2010), the IEEE MTT-S Tatsuo Itoh Prize (2014), and the Best Industrial Paper Award at IEEE MTTS-IMS2016 (2016). 